\title{
A New Paradigm for Metallic Alloys in Materials Science
}

\author{
Y. Ustinovshikov \\ Ural Division of Russian Academy of Sciences, Physical-Technical Institute, Izhevsk, Russia \\ Email: ust@ftiudm.ru
}

Received 25 June 2015; accepted 28 July 2015; published 31 July 2015

Copyright (C) 2015 by author and Scientific Research Publishing Inc.

This work is licensed under the Creative Commons Attribution International License (CC BY). http://creativecommons.org/licenses/by/4.0/

(c) (i) Open Access

\begin{abstract}
In the article, taking into account the phase transition "ordering-phase separation" discovered in alloys, new concepts about the diffusion phase transformations in alloys are formulated: chemical interaction between dissimilar atoms exists always in all alloys and at any temperature of heating; alloys offer a surprising and not previously known property of changing the sign of the chemical interaction between dissimilar atoms at a change of the temperature or composition of alloys; diffusion processes occurring in alloys at different temperatures depend on the sign and the absolute magnitude of the energy of the chemical interaction between dissimilar atoms. All these three concepts are analyzed in detail, by the example of Ni-based and Co-based binary alloys using experimental results obtained by transmission electron microscopy. It is shown, on these ideas, how to carry out heat treatment of alloys more rationally, what principles should underpinned in the base of the construction of phase diagrams, how the microstructures of ordering and phase separation affect some properties of alloys.
\end{abstract}

\section{Keywords}

Phase Transitions, Transmission Electron Microscopy, Microstructure, Phase Diagrams

\section{Introduction}

The existing ideas about the microstructure of metallic alloys were formed as far back as the first half of the twentieth century. They were based on experiments being carried out on liquid molecular solutions, which showed that the solubility of salt in water increased with increasing temperature. Although the nature of the intermolecular interactions in aqueous solutions was very different from the nature of the atomic interactions in metallic solid solutions, they believed that if the kinetics of precipitation of crystals of excess phase from the aqueous solution and the kinetics of precipitation of particles of a new phase from the metallic solid solution 
were similar, then the mechanism of these processes should be one and the same. This was how such concepts as the solubility of atoms of one component in the lattice of the other, direct dependence of solubility on temperature, the supersaturated solid solution, etc., were taken from the theory of aqueous solutions appeared in the theory of alloys. They believed that the solubility at some temperature depended mainly on the ratio of the sizes of the solvent and the solute atoms. At the same time, they believed that chemical interactions between dissimilar atoms in solid solutions began to appear only when the atoms of the solute were involved in formation of particles of a new phase. Up to this moment, as they were believed, the chemical interactions between dissimilar atoms did not manifest themselves. They considered the disordered solid solution to be the initial phase, supposing that at high temperatures it was the equilibrium phase, in which the component atoms were chaotically distributed over the lattice sites (substitutional alloys) and interstices (interstitial alloys) [1]. At a decrease of the temperature, when the atomic interaction potential became substantially larger than the thermal energy, the mutual arrangement of component atoms in the solid solution was determined from the condition of the minimum free energy of the alloy [1] and an order-disorder phase transition began in it. It was considered that the physical reason for ordering was an elastic interaction between the component atoms constituting the solid solution [1].

This very principle was used in the construction of equilibrium phase diagrams: in them, in overwhelming majority of cases, regions of solid solutions were shown at high temperatures, and two-phase regions at low temperatures. In heat treatment practice, a two-stage scheme "high-temperature quenching + tempering (aging)" was mainly used, which presupposed that before getting a desired microstructure of the alloy, it was necessary to form the microstructure of a disordered solid solution, i.e., to quench the alloy in water from a high temperature. All these ideas, formed about 100 years ago, when modern methods of investigation of the crystal structure of alloys did not yet exist, flourish in Materials Science until now, still virtually intact.

Experimental studies of the crystal structure of alloys conducted later with the help of X-ray diffraction (XRD), seemed to have fully confirmed these views. Indeed, when this method was applied to alloys quenched from high temperatures, no other phases besides the solid solution were found. On the basis of these data, they came to the conclusion that at high temperatures, the microstructure of alloys was a disordered solid solution, which fully coincided with the thesis that the solubility of one component in the lattice of the other rose with temperature.

However in the sixties-seventies of the XX century, when the method of transmission electron microscopy (TEM) became widely used in the study of the microstructure of alloys, many authors were surprised to find that the microstructure of many alloys, quenched from the region of solid solutions, was two-phase and contained either particles of a new phase in the solid solution or modulations of the composition. Examples that have become classic are alloys of the systems Ni-Mo [2], Fe-Be [3], Al-Zn [4], Cu-Be [5], Nb-Zr [6] and many others, which, according to phase diagrams, at high temperatures, had regions of the solid solution. Detection of such two-phase microstructures was sometimes attributed to the fact that the regions of the solid solution in the phase diagrams had not been determined accurately enough [6]. In most cases, however, they agreed in the opinion, that the decomposition of alloys proceeding via the spinodal mechanism, occurred during the very process of quenching, i.e., a very short period of time, comparable with the time of cooling the alloy in water. The last point was explained by the fact that during spinodal decomposition, the stage of critical nuclei formation was absent [2]-[5]. This explanation contradicts both Cahn's theory of spinodal decomposition (Cahn considered spinodal decomposition as a diffusion process) and experimentally determined magnitudes of diffusion coefficients, which are by four orders of magnitude lower than it is necessary for the formation of new phase particles to occur during cooling of the alloy in water.

Not to become a prisoner of these "singularities" of quenching, we must recollect how existing now phase diagrams were constructed. The times when the X-ray diffraction analysis was considered to be almost the only direct method allowing to determine the phase composition of alloys in this or that point of the phase diagram passed long ago but phase diagrams constructed with the help of the method at that time, continue to be a general aid for researchers. However, as far back as his time, Guinier pointed out that XRD was unable to identify second-phase particles with sizes smaller than the regions of coherent X-ray scattering [7]. This meant that all highly dispersed phases, which precipitate in alloys of these or those systems could not be registered by the XRD method and, therefore, were absent in existing equilibrium phase diagrams of these systems. In its turn, the latter circumstance could be interpreted as the fact that the solid-solution regions in the phase diagrams are not solid-solution regions as such, but two-phase regions. In this connection, the main role of a tool to be used for determining the phase composition of alloys in this or that point of the phase diagram should be given to a local 
method of research - transmission electron microscopy. As it was noted, in studies conducted with this method, it had been found that phase composition of many alloys in fact did not correspond to the composition of the regions shown in existing phase diagrams.

The conclusion that the solid-solution regions in equilibrium phase diagrams are in fact two-phase regions agrees with the well-known axiom of thermodynamics that in nature all solutions are non-ideal and have either positive or negative deviations from Raoult's law. This can lead to decomposition of such solutions at the higher temperatures of heating also. If the regions in the phase diagram, which are now referred to as regions of solid solutions are in fact two-phase regions, then quenching in water from such a region will also lead to fixation of a two-phase structure, not a solid solution at all.

As is well known, ideal solutions are not normally found_in nature and, therefore, one should expect that any solid solution, in any alloy, at temperatures sufficient for diffusion of species over long distances, is bound to decompose (Solutions close to ideal may be observed only at very high dilution). However, in all known equilibrium phase diagrams, the areas of the solid solution are considered as an equilibrium phase. The sign of the ordering energy was usually determined by the method of measuring the partial pressure of the vapors of components at temperatures close to the melting point. Since at a decrease of the temperature this pressure abruptly drops, and, beginning with certain temperatures, it is impossible to measure it, then it was tacitly assumed that the sign of the ordering energy determined at very high temperatures remains the same at lower temperatures as well. This gave birth to the idea that each binary system is characterized by its own sign of the ordering energy, which is constant for this system at any temperature.

Thus, the existing conceptual views about these or those processes occurring in alloys constantly come into conflict with experiment. The situation in this area of knowledge began to change only when it had been proved that the chemical interactions between component atoms exist always, in all alloys and at any temperature (even in the liquid state), that alloys have a surprising and not previously known property of changing the sign of the chemical interaction between the dissimilar atoms at a change in the temperature of heating (sometimes at a change in the concentration of the alloy). In other words, our understanding of the nature of alloys began to change only when the phase transition "ordering-phase separation" was experimentally discovered [8]. This transition occurs at a temperature specific for each system, at which the sign of the chemical interaction between atoms of A and B is reversed. Earlier it was considered that each binary system had its own sign (plus or minus) of the chemical interaction energy, which was constant for this system at any temperature. Now, when the transition "ordering-phase separation" in alloys has been discovered, this idea is being revised. Today, it is clear that in every system, the sign of the chemical interaction energy can change at a change in the temperature, sometimes more than once. At first, the transition occurs at the level of changes in the electronic structure of the alloy, as evidenced by a change in the shape of the valence bands of the X-ray photoelectron spectra, determined by the method of XPS [9] [10]. The change of the sign of the chemical interaction between dissimilar atoms changes the direction of diffusion between them to the opposite one, which affects a change in the type of microstructures [11] [12].

It has been shown experimentally that atoms of any one component can participate in the formation of a chemical compound with atoms of another component only if the sign of their chemical interaction is negative [9] [10]. If the sign of the chemical interaction energy between the dissimilar atoms is positive, then there takes place a process of phase separation of an alloy into clusters (grains) consisting of atoms of any one sort, which in conventional phase diagrams is commonly presented as formation of eutectics (eutectoids). Such a transition from one type of the chemical interaction (attraction between dissimilar atoms) to another type (repulsion between them) naturally passes through the point, where the energy of the chemical interaction is zero, i.e. where the microstructure of a disordered solid solution is to be formed [13]. Therefore, the discovery in 1996, of the phase transition "ordering-phase separation" [8], occurring (as it turned out later) in alloys of a large number of systems, allowed to overcome many of these contradictions, allowed to reach a consensus with thermodynamics, and also allowed to correct our concepts in accordance with experimental results. It is these issues that the present article addresses to.

\section{The History of the Discovery of the Phase Transition "Ordering-Phase Separation"}

\subsection{Alloys of the Fe-Cr System}

In thermodynamics, it is assumed that if the sign of the deviations from Raoult's law has been determined at any 
single range of the temperatures, this sign is preserved at all other heat treatment temperatures of the alloy. In alloys of the $\mathrm{Fe}-\mathrm{Cr}$ system, positive deviations from Raoult's law were found at high $\left(1040^{\circ} \mathrm{C}-1400^{\circ} \mathrm{C}\right)$ temperatures by the vapor-pressure method [14]. However, at temperatures of $440^{\circ} \mathrm{C}-830^{\circ} \mathrm{C}$, a chemical compound ( $\sigma$-phase) was detected in alloys of Fe-Cr system, though, as is generally known, its formation is possible only at negative deviations from ideality. At the same time, according to reference book on phase diagrams [15], phase separation structures were found not only at high temperatures $\left(1040^{\circ} \mathrm{C}-1400^{\circ} \mathrm{C}\right)$ but at temperatures below $550^{\circ} \mathrm{C}$ as well. Such contradictions existing in the phase diagram of $\mathrm{Fe}-\mathrm{Cr}$, made the authors [8] set themselves the following questions: Why does the chemical compound- $\sigma$-phase form in $\mathrm{Fe}-\mathrm{Cr}$ alloys at positive deviations from ideality? Why do positive deviations from Raoult's law occur at high temperatures, whereas phase separation structures are found only at low $\left(550^{\circ} \mathrm{C}\right.$ and below) temperatures? What is the sign of the chemical interactions in the temperature range of $440^{\circ} \mathrm{C}-550^{\circ} \mathrm{C}$, which is marked in the phase diagram as belonging to both the regions: phase separation and ordering? To answer these questions and resolve the contradictions, the authors [16] [17] conducted a detailed structural study of five binary alloys containing $10 \%$ to $50 \%$ chromium (the rest is iron) over a wide temperature range (up to $1400^{\circ} \mathrm{C}$ ).

Electron microscopy studies of Fe-Cr alloys, quenched in water from temperatures of $1200^{\circ} \mathrm{C}-1400^{\circ} \mathrm{C}$, led to unexpected results. The microstructure of the studied alloys after such quenching was not a solid solution at all. Figure 1 shows microstructures (a) and the electron diffraction pattern (b) of the $\mathrm{Fe}_{50} \mathrm{Cr}_{50}$ alloy after quenching in water from $1200^{\circ} \mathrm{C}$. Two types of particles are detected in Figure 1(a): 1) coarse particles along the crystallographic directions of the matrix and 2) small disperse particles, which are randomly located in the rest of the matrix. The bright fields surrounding the coarse particles (Figure 1(a)) testify that the latter are formed at the expense of the dissolution of disperse particles. The electron diffraction pattern taken from a coarse particle in Figure 1(a) shows satellites near the fundamental reflections (Figure 1(b)). Such an electron diffraction pattern may be interpreted as obtained from two solid solutions with different lattice parameters-depleted (bright fields) and enriched in chrome (dark precipitates).

The first attempt to verify experimental results indicating the existence of high-temperature phase separation in $\mathrm{Fe}-\mathrm{Cr}$ alloys was made using TEM [18]. After water quenching from $1200^{\circ} \mathrm{C}$, the $\mathrm{Fe}-45 \% \mathrm{Cr}$ alloy had the same microstructure that is shown in Figure 1(a). However, the authors [18] believed that such a microstructure could be the result of any processes other than high-temperature phase separation. They classified the precipitates presented in Figure 1(a) as "foreign" phases, namely, as chromium nitrides $\mathrm{CrN}$. They thought that when heat treated in low vacuum (heating in quartz ampoules) as in Refs. [8] [16] [17], iron-chromium alloys were saturated with air nitrogen to concentrations of the order of 1 at\% [18]. Even if we agree with the authors [18] that $\mathrm{Fe}-\mathrm{Cr}$ specimens sealed in evacuated quartz ampoules can be saturated with nitrogen to a concentration of 1 at $\%$ at $1200^{\circ} \mathrm{C}$, then we should admit that this saturation will lead to formation of nitrides ( $\left.\mathrm{CrN}\right)$, in the amount of no more than 1 vol.\%. It undoubtedly contradicts Figure 1(a), in which the volume fraction of dark precipitates is about $50 \%$.

The second attempt was made when the $\mathrm{Fe}_{51} \mathrm{Cr}_{49}$ alloy quenched from the temperatures of $900^{\circ} \mathrm{C}-1185^{\circ} \mathrm{C}$ was investigated [19] One should bear in mind that this range of temperatures is somewhat below the interval of phase separation $\left(1200^{\circ} \mathrm{C}-1400^{\circ} \mathrm{C}\right)$. Using the Mossbauer spectroscopy method, the authors [19] expected to

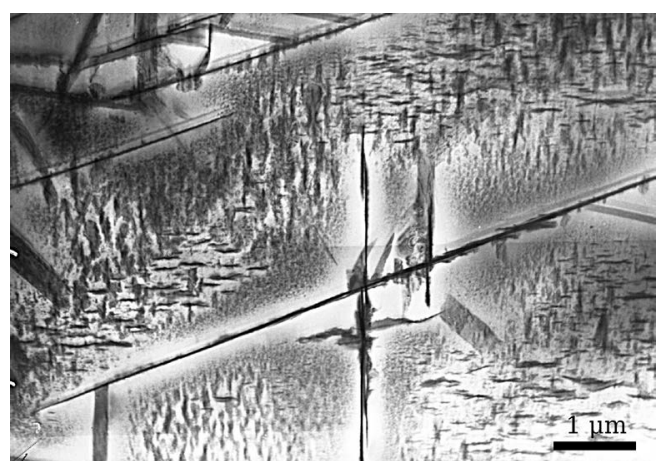

(a)

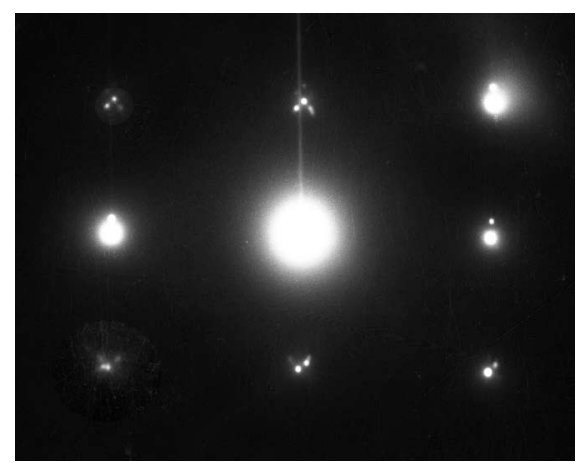

(b)

Figure 1. $\mathrm{Fe}_{50} \mathrm{Cr}_{50}$ alloy .Water-quenching from $1200^{\circ} \mathrm{C}$ : (a) Bright-field micrographs; (b) Electron diffraction pattern taken from the coarse particle in (a). 
observe that the partial gamma-resonance peak corresponding to pure iron would grow with an increase of alloy decomposition. However, their expectations did not come true. Based on the above fact, they concluded that high-temperature phase separation did not occur in Fe-Cr alloys. Indeed, using TEM, phase separation microstructures are not found after heat treatment at $900^{\circ} \mathrm{C}-1185^{\circ} \mathrm{C}$, but they are always found after heat treatment in the temperature range of $1200^{\circ} \mathrm{C}-1400^{\circ} \mathrm{C}$ [16] [17].

According to the accepted phase diagram of $\mathrm{Fe}-\mathrm{Cr}$ [15], in the temperature range of $440^{\circ} \mathrm{C}-830^{\circ} \mathrm{C}$, there is a region of the $\mathrm{FeCr}$ chemical compound ( $\sigma$-phase). The formation of such a phase is possible only when the deviations from ideality have a negative sign. Based on this, we can conclude that in this temperature range the sign of the chemical interaction between the atoms of $\mathrm{Fe}$ and $\mathrm{Cr}$ is negative. Such a conclusion automatically implies the existence of a phase transition, which, at a temperature decrease from the range of $1200^{\circ} \mathrm{C}-1400^{\circ} \mathrm{C}$ to $440^{\circ} \mathrm{C}$ $-830^{\circ} \mathrm{C}$, should result in the change of the sign of the chemical interaction between the atoms of the components.

However, as far as $\sigma$-phase precipitation is concerned, the conclusion that the sign of the deviations from ideality at such a precipitation will necessarily be negative, does not find understanding with some authors. This is due to the fact that in Fe-Cr alloys, the $\sigma$-phase is formed only in a thin surface layer of the specimen [20] [21]. Based on these data, Turchi, Reinhard and Stocks [22], referring to the positive deviations from Raoult's law revealed at high temperatures [14], believed that these deviations should exist in this system at all other temperatures. They concluded that the sign of the deviations from ideality in the Fe-Cr system depends on who wins in the competition between the "macroscopic" tendency to phase separation and the "local chemical" tendency to ordering. They reasoned that each of the tendencies is characteristic of a certain coordination sphere; phase separation, for example, is characteristic of the first coordination sphere, whereas ordering is characteristic of all other coordination spheres. Moreover, they considered the formation of the $\sigma$-phase at $440^{\circ} \mathrm{C}-830^{\circ} \mathrm{C}$ not as the result of the tendency to ordering, but as one of "the phenomena pertaining to surfaces (reconstruction, segregation, etc.)" [22]. The $\sigma$-phase is really formed on free surfaces [20] [21]; however, it does not mean that it is not a chemical compound [23], and, therefore, its formation is not pre-determined by the tendency to ordering. Ohnuma et al. [24] thought that the presence of the $\sigma$-phase in the Fe-Cr system, in which positive deviations from Raoult's law were observed at high temperatures, was due to the magnetic contribution to the Gibbs energy. They supposed that the interaction between chemical and magnetic ordering influenced both the magnetic properties of alloys and the thermodynamics and kinetics of atomic ordering. However, they did not find any convincing experimental evidences of such influence in the literature.

The X-ray diffraction patterns obtained from the surface of the $\mathrm{Fe}_{50} \mathrm{Cr}_{50}$ alloy specimen after heat treatment at different temperatures and exposures indicate the formation of a dense continues layer of the $\sigma$-phase on the surface. The maximum depth of the surface layer of the $\sigma$-phase reaches $0.4 \mathrm{~mm}$ [16]. The $\sigma$-phase was not found in the internal volume of the specimen even after prolonged heat treatment [16] [22]. It was considered [22] that the reasons for this were high elastic stresses that arise when the bcc lattice of the solid solution transforms into the tetragonal lattice of the $\sigma$-phase. Therefore, such a transformation takes place only near the free surface of the specimen. It was found that the $\sigma$-phase in the surface layer is formed not by simultaneous transformation of the lattice over the whole transformed volume of the surface layer, but through gradual precipitation of separate particles inside the surface layer, and then, a subsequent "collapse" of the space between these particles (Figure 2) [16]. This phase was found only in alloys, whose composition was close to equiatomic. For

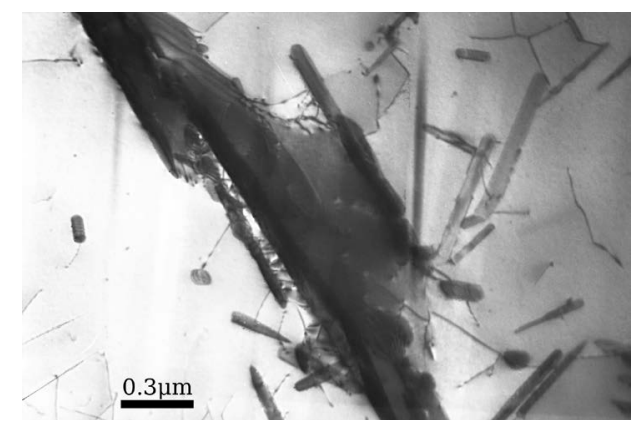

Figure 2. $\mathrm{Fe}_{50} \mathrm{Cr}_{50}$ alloy water-quenched from $1200^{\circ} \mathrm{C}$ and then heat treated at $700^{\circ} \mathrm{C}$ for $100 \mathrm{~h}$. The $\sigma$-phase particles in the surface layer [16]. 
example, in the $\mathrm{Fe}_{60} \mathrm{Cr}_{40}$ alloy, using the XRD method it is possible to observe only very weak lines of the $\sigma$-phase [16].

In the accepted $\mathrm{Fe}-\mathrm{Cr}$ phase diagram, the existence regions of low-temperature phase separation and the $\sigma$-phase are shown under the same miscibility gap and within the same temperature range $\left(440^{\circ} \mathrm{C}-550^{\circ} \mathrm{C}\right)$, i.e. the region of the $\sigma$-phase and the region of low-temperature phase separation are superimposed [15]. Obviously, the existence of the two opposite tendencies - the tendency to ordering (when $\mathrm{Fe}$ and $\mathrm{Cr}$ atoms are mutually attracted and form the $\sigma$-phase) and the tendency to phase separation (when $\mathrm{Fe}$ and $\mathrm{Cr}$ atoms are mutually repulsed and form Cr-enriched clusters in the Cr-depleted matrix) at the same points of the phase diagram is hardly probable. Indeed, the minimum temperature at which we can still find traces of the $\sigma$-phase on the surface of the specimen is $570^{\circ} \mathrm{C}$ [16] [17]. At $550^{\circ} \mathrm{C}$ and below, a microstructure of phase separation was found with the help of the TEM method; in the $\mathrm{Fe}_{70} \mathrm{Cr}_{30}$ alloy, for example, it was observed in the form of small round particles enriched with chromium, which precipitated in the Cr-depleted matrix [16] [17].

The presence in the same phase diagram, for example in Fe-Cr, of 1) a region, in which a new phase appears in the form of chemical compounds $\sigma$ (the tendency to ordering) and 2) a region where the phase separation microstructure is formed (the tendency to phase separation), naturally suggests, that somewhere in the Fe-Cr phase diagram, there must be a boundary separating these regions. On this boundary, the tendency to ordering should be replaced by the tendency to phase separation, i.e. the chemical interaction between component atoms should reverse its sign. It turns out that this boundary can be determined due to the fact that the sign of the chemical interaction in Fe-Cr alloys does not change simultaneously in the entire volume of the alloy. First, it changes only in some microscopic portions of the alloy and only then in the rest part of it. The state when some microscopic portions of the alloy having the positive sign of the chemical interaction coexist with other microscopic portions having the negative sign, can be observed with the use of TEM [16] [17].

In order to expose the microscopic portions, it is necessary to carry out a double heat treatment: for example, first, in the temperature range, in which the tendency to phase separation appears and then in the temperature range, in which the tendency to ordering occurs, or vice versa. In both cases, the exposure time at this or that temperature is determined empirically. If the $\mathrm{Fe}_{50} \mathrm{Cr}_{50}$ alloy which after a proper heat treatment has the microstructure of high-temperature phase separation, is heat treated in the temperature range corresponding to $\sigma$-phase formation $\left(700^{\circ} \mathrm{C}-800^{\circ} \mathrm{C}\right)$, then, the microstructure of high-temperature phase separation begins to dissolve and, in its place, these microscopic portions designed as "chemical domains" become visible on TEM images (Figure 3). These domains were first found in Ref. [16] [17] and named for electron domains. They are considered as microscopic portions, inside of which the sign of the ordering energy has already changed for the opposite relative to the surrounding other portions, in which the sign is still positive. An electron beam passing through the foil, in which chemical domains have formed, should deviate in opposite directions on both sides of the domain boundary and it leads to a deficiency (bright lines) or an excess (dark lines) of electrons at defocusing the electron microscopic image [17]. It should be noted here, that similar domains are observed in electron micrographs of the alloys at their transition both in the ferromagnetic state (when the domains differ in the magnetization vector orientation), and in the ferroelectric state, (when the difference is in the direction of spontaneous polarization). It means that the nature of the contrast from all the above-mentioned domains is the same and the contrast is formed due to the difference in the electronic structure of neighboring domains.

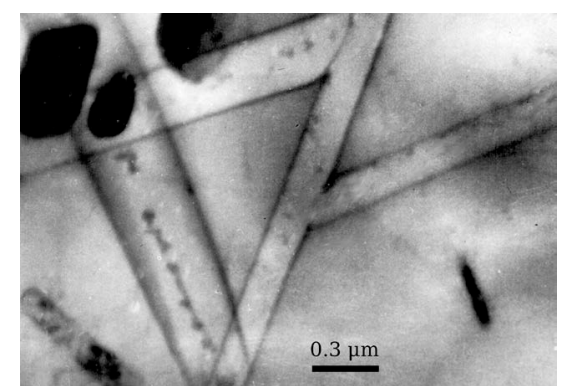

(a)

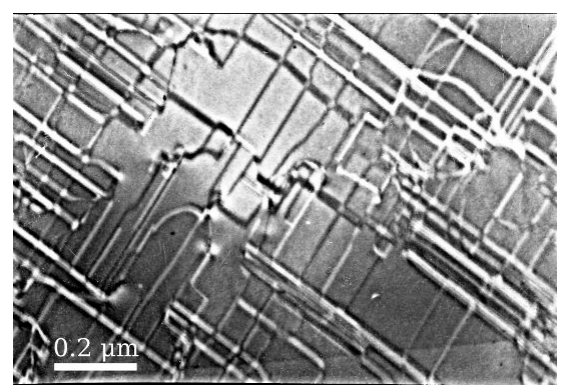

(b)

Figure 3. $\mathrm{Fe}_{50} \mathrm{Cr}_{50}$ alloy. Chemical domains (a) formed at high-temperature transition "ordering-phase separation” (water-quenching from $1200^{\circ} \mathrm{C}$ and then water-quenching from $700^{\circ} \mathrm{C}$ for $8 \mathrm{~h}$ ) and (b) formed at low-temperature transition "ordering-phase separation" (water-quenched from $700^{\circ} \mathrm{C}$ for $8 \mathrm{~h}$ and then from $550^{\circ} \mathrm{C}$ for $4 \mathrm{~h}$ ). 
Therefore, we think that the name of the domains formed at the phase transition "ordering-phase separation" should reflect the feature which makes them different from ferromagnetic and ferroelectric domains. A suitable term for these domains would be "chemical domains" since the neighboring domains differ from one another in the sign of chemical bonds. A similar picture is observed, when under change of temperature the alloy transforms from the region of ordering ( $\sigma$-phase) into the low-temperature phase separation region. Figure 3(b), for example, shows chemical domains observed in the $\mathrm{Fe}_{50} \mathrm{Cr}_{50}$ alloy, first heat treated at a temperature corresponding to the region of ordering $\left(700^{\circ} \mathrm{C}\right.$ for $\left.8 \mathrm{~h}\right)$ and then at a temperature corresponding to the region of low-temperature phase separation $\left(550^{\circ} \mathrm{C}\right.$ for $\left.4 \mathrm{~h}\right)$. The above two-stage heat treatment allows assessing the temperature of the phase transition "ordering-phase separation" with an accuracy of $\pm 50^{\circ} \mathrm{C}$ (high-temperature) and $\pm 10^{\circ} \mathrm{C}$ (low-temperature phase transition) [17] [25].

It was thought, that with prolonged aging at the same temperature, the domains formed as a result of the high-temperature transition would disappear and the tendency toward ordering would be present in the entire volume of the alloy. However, prolonged aging of up to $100 \mathrm{~h}$ at $700^{\circ} \mathrm{C}$ and $20 \mathrm{~h}$ at $800^{\circ} \mathrm{C}$ has shown that the domains are still present. It means that such a domain structure at these temperatures is metastable. Hence, it becomes clear why the $\sigma$-phase is formed only at the specimen surface and does not spread out into its depth: at $570^{\circ} \mathrm{C}-830^{\circ} \mathrm{C}$, the tendency to ordering in the studied alloy dominates only in a thin surface layer; in the specimen bulk, a domain structure is retained, within which portions where the ordering energy is positive, alternate with portions where it is negative. The structure of such chemical domains has been found up to now in alloys of the Fe-Cr system. Therefore, in alloys of other binary systems studied (Fe-Co [9], Fe-Mn [26], Fe-Ti [27], Fe-V [28], Fe-Mo [29], Fe-W [30]), the temperature of the phase transition "ordering-phase separation" was determined by the change in the type of the microstructure.

Fe-rich portion of the Fe-Cr phase diagram is shown in Figure 4 [17]. It was constructed on the evidence of

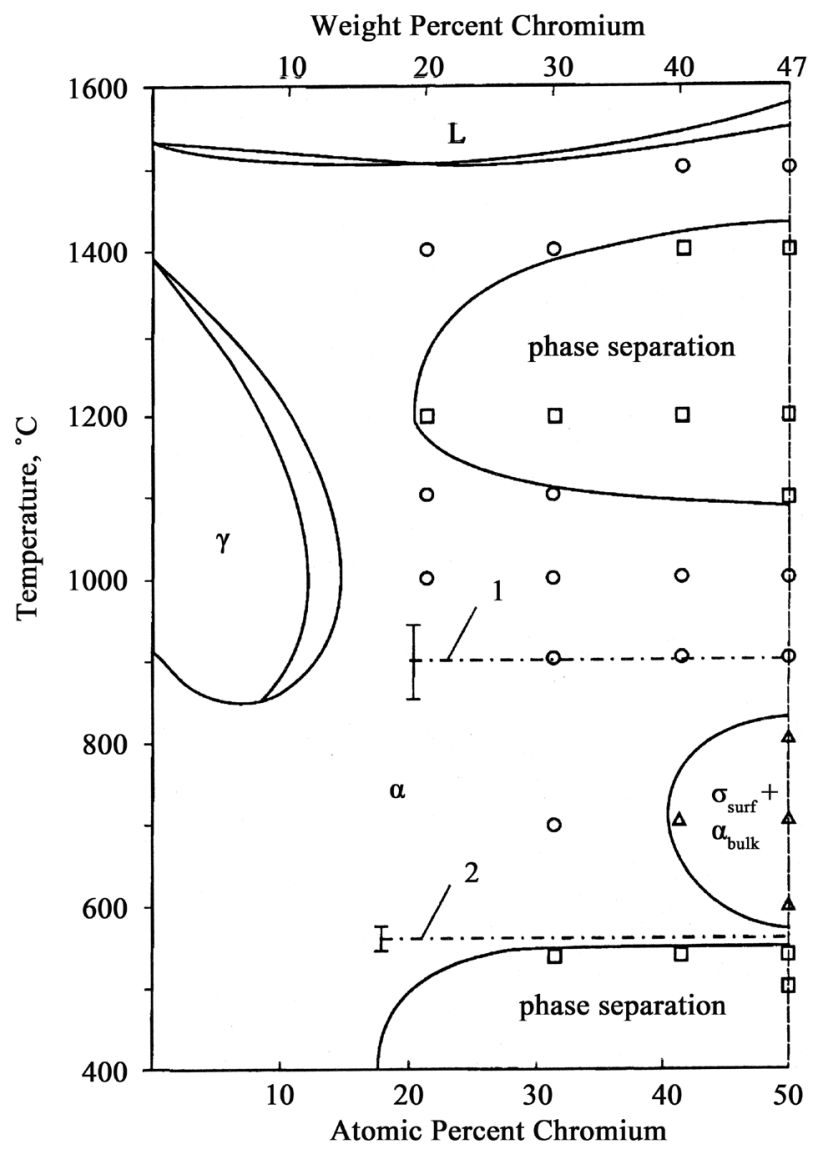

Figure 4. The Fe-rich portion of the Fe-Cr phase diagram. Dashed lines show the temperatures of phase transition "ordering-phase separation”. Designations: o- solid solution microstructure; $\square-$ phase separation microsructure; $\Delta-\sigma$-phase at the surface (tendency to ordering). 
the TEM studies. The lines of phase transitions “ordering-phase separation” are indicated by numerous: 1-hightemperature; 2-low-temperature phase transition. At temperatures lying in the vicinity of these lines, the microstructure of alloys is a disordered solid solution, which can be fixed by quenching the alloy from these temperatures.

\subsection{Alloys of the Fe-C System}

To answer the question, whether an identical phase transition occurs in interstitial alloys, alloys of the Fe-C system have been chosen for investigation [31]. In these alloys there are two types of microstructures, namely, microstructures formed as the result of the tendency to phase separation (solid solution of carbon in iron + graphite) and microstructures formed as the result of the tendency to ordering ( solid solution of carbon in iron + cementite).

Graphitization of high-carbon tool steels has been known for a long time [32]. In 1970 - 80 s, it was found that graphitization of hypereutectoid $(1.1-1.67 \mathrm{wt} \% \mathrm{C})$ steels occurred in the temperature range of $950^{\circ} \mathrm{C}$ $1223^{\circ} \mathrm{C}$. For example, Izotov et al. [33], Nagakura et al. [34], Kusunoki et al. [35], Tyapkin et al. [36], Sandvik et al. [37] discovered disorderly located clusters of $\mathrm{C}$ atoms and a microstructure consisting of strongly C-enriched and C-depleted modulations(without any traces of cementite). They believed that formation of carbon clusters happened immediately after water quenching, at room temperature, during a very short interval (e.g. not more than $5 \mathrm{~min}$ ). The authors [33] called this behavior of hypereutectoid steels "abnormal".

In recent years, the Fe-C phase diagram has received little attention. It is thought that the diagram has been much studied and all transformations operating in the microstructure of steels and cast irons are well understood. However, in 2009, they once again raised the question of how to explain the contradictions existing in the phase diagram of Fe-C, such as graphitization of steels at high temperatures, presence of the metastable and stable versions of the diagram, and so on [31].

As shown by Kusunoki [35], satellite spots in the electron diffraction pattern become intense with increasing the carbon content in steel and can be observed in steels containing no less than $0.2 \mathrm{wt} \%$ C. Similar to substitution alloys, the appearance of such satellites could be considered as the indicator of the formation of two solid solutions with different lattice parameters, i.e. as the indicator of phase separation [31]. The microstructure shown in Figure 5 [31] is a typical example of the morphology of carbon clusters in the Fe-1.31\% C alloy as-quenched from high temperatures.

The existing Fe-C phase diagram has been used for presentation of the microstructure data obtained by different authors [31] [33]-[37] (Figure 6). By virtue of the fact that graphite particles and carbon clusters were found experimentally in the temperature range from eutectic to eutectoid, the entire high-temperature part of the phase diagram is shown as a uniform existence region of two phases, namely, carbon which is not chemically bound with iron (C clusters or graphite) and austenite. It is a region, in which the tendency toward phase separation leads to the formation of the phase separation microstructure. Obviously, the morphology of the alloys in this region strongly depends on the carbon content in them. For example, for compositions corresponding to cast irons, the phase separation into iron and particles of graphite takes place; for compositions corresponding to steels (from $0.2 \%$ to $1.67 \% \mathrm{C}$ ) the observed precipitations are clusters of carbon atoms; for the compositions with a small concentration of carbon (below $0.2 \%$ ), austenite can be considered as an infinitely diluted solid solution, i.e. a solution obeying Henry's law.

The electron microscopic results also show that quenching of the investigated steel from a temperature of $790^{\circ} \mathrm{C}$ in water does not lead to formation of carbon clusters (indicated by a blank box in the phase diagram, Figure 6) [31]. Since cementite in the microstructure of steels is found only after heat treatment at temperatures below the eutectoid and never above it, it can be assumed that the eutectoid line is at the same time the line of the phase transition "ordering-phase separation". This means that above it, there takes place a tendency to phase separation, and graphitization occurs in alloys (and steels and cast irons). The presence of graphite in the structure of cast irons below the eutectoid line (below the line of the phase transition "ordering-phase separation") is quite explicable: the very large sizes of graphite particles formed mainly in the liquid solution, do not give them an opportunity to dissolve while cooling the casting or during isothermal aging of the alloy below the eutectoid temperature. All these data allow us to consider the phase diagram of $\mathrm{Fe}-\mathrm{C}$ in a somewhat different light than it is presented in reference literature (Figure 6). In it, the austenite(A) + cementite region is absent, as above the line of the phase transition "ordering-phase separation" cementite cannot exist. 


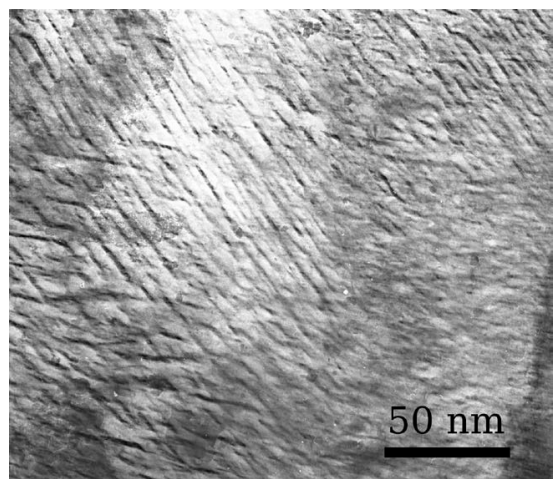

Figure 5. Fe-1.31\%C alloy water-quenched from $1150^{\circ} \mathrm{C}$ : bright-field image.

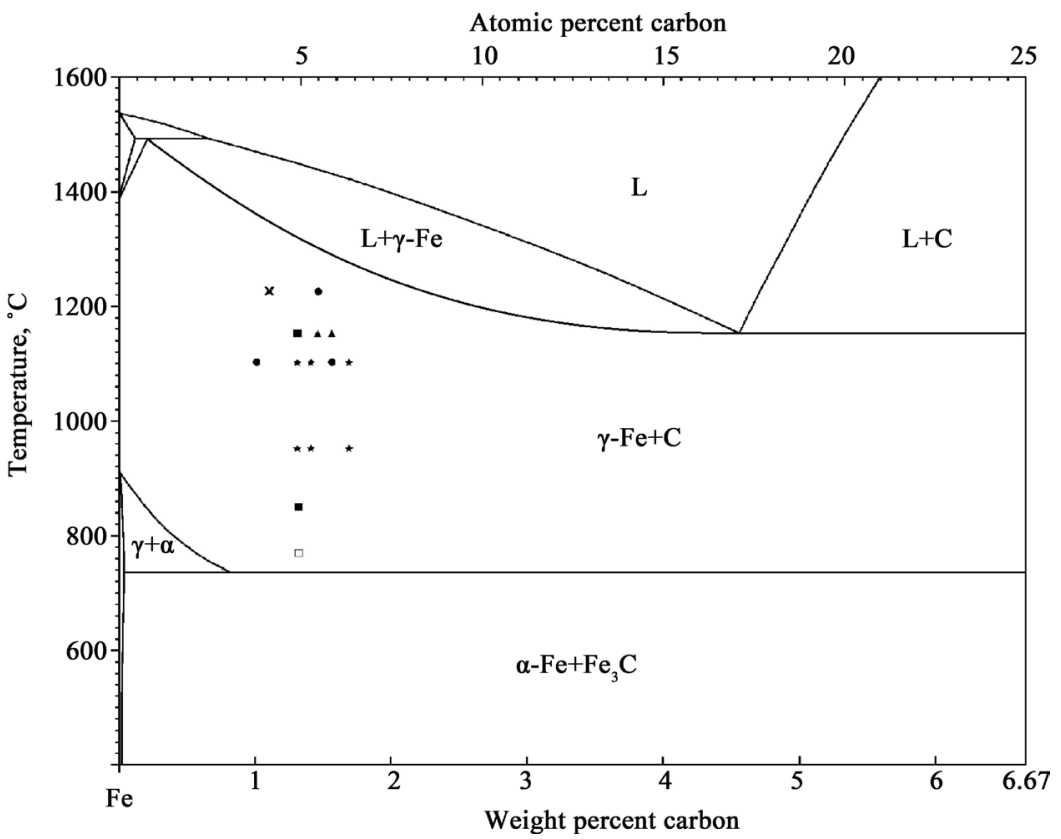

Figure 6. Fe-6.67\% C phase diagram. Carbon clusters revealed by Izotov and Utevsky [33] are designated as •; Nagakura et al. [34] and Kusunoki [35] as *, Tyapkin et al. [36] as $\mathbf{\Delta}$; Sandvik and Wayman [37] as x; data obtained in Ref. [31] are designated as - (if carbon clusters are found in the martensite structure) and as $\square$ (if they are not found).

\subsection{The Technique for Determining the Sign of the Deviations of the Solid Solution from Ideality at Different Temperatures}

The determination of the sign of the chemical interaction (ordering) energy was usually performed by measuring the partial pressure of the vapors of components at temperatures close to the melting point of the alloy under study. Since at a decrease of the temperature, this pressure abruptly drops, and, beginning with certain temperatures, it is impossible to measure it, then it was tacitly assumed that the sign of the ordering energy determined at very high temperatures remains the same at lower temperatures, as well. As was noted in Ref. [38], this gave birth to the idea that each binary system is characterized by its own sign of the ordering energy, which is constant for this system at any temperature. Other methods were also used, for example, measurement of the molar volume by the stationary droplet method. With the help of this method, they determined [39] that, for example, in the $\mathrm{Ni}_{73} \mathrm{Co}_{27}$ liquid alloy, negative deviations of the partial molar volume from ideal mixing take place. In another study [40], using the method of Knudsen cell mass spectrometry, they came to the conclusion that Ni-Co alloys (including the $\mathrm{Ni}_{73} \mathrm{Co}_{27}$ liquid alloy) are a regular solution with a slightly positive enthalpy of mixing. These results testify that the using in thermodynamics methods for determining the sign of the ordering energy are far from being perfect and are unable to determine the sign of deviations from ideality at relatively low temperatures. 
Before considering a new technique for determining the sign of the ordering energy at any heat treatment temperature of the specimen, we would like to dwell on the question of using the term "ordering energy" (energy of mixing, enthalpy of mixing, and so on). Any one of the above terms corresponds not quite exactly to the physical meaning of the energy that appears in an $\mathrm{AB}$ alloy at the interaction of two dissimilar atoms of $\mathrm{A}$ and $\mathrm{B}$. When the sign of the interaction is negative (atoms of $A$ and $B$ attract each other), then a tendency to ordering appears in the alloy and chemical compounds are formed. When the sign is positive (atoms of A and B repulse each other), then a tendency to phase separation occurs and clusters are formed. Therefore, it makes sense to use a term, which is common for these two cases, and call such energy the energy of the chemical interaction [41]. Hereinafter, we will use exactly this term.

The use of the method of XPS (which, as it is commonly believed, is a method for investigation thin surface layers of material) for determining the sign of the energy of the chemical interaction in alloys is based on the assumption , that in high vacuum, at increasing the temperature of heating, rapid evaporation of atoms from the specimen surface begins. This leads to the fact, that the information obtained under such experimental conditions, concerns already the entire volume of the specimen, not only its thin surface layer. The sign of the energy of the chemical interaction was determined by the change in the shape of the valence bands at each of the studied temperatures. If the shape of the valence band of the alloy is similar to the shape of the valence band of the pure A solvent as a result of a stronger spatial localization of the electron density of the solvent in the vicinity of its own atoms, then it means that in the immediate environment of $A$ atoms there are $A$ atoms. In this case, we can say, that A-A and B-B bonds form in the alloy, i.e. there is a tendency to phase separation. If the distribution of the density of 3d-states in the alloy is similar to the distribution of the electron density in the valence band of the dissolved component, then we can say, that in the alloy, at this temperature, there are no A-A bonds between the atoms of the solvent and, therefore, each atom of the A solvent is involved in a bond with atoms of the dissolved B component. This means, that a tendency to ordering takes place in the alloy.

The change of the sign of the chemical interaction between the component atoms leads to a reverse in the direction of diffusion fluxes in the alloy, and, as a consequence, a change in the type of microstructures. If the alloy displays a tendency to ordering, then chemical compounds are formed in the structure, if it displays a tendency to phase separation, then clusters (or grains) are formed, consisting mainly of atoms of one kind. In the phase transition point, the sign of the ordering energy of the alloy passes through zero and, therefore, we can assume that at temperatures close to this point, there forms a structural state close to the state of a completely disordered solid solution [9] [42] [43]. However, this state appears only in the immediate vicinity of the temperature of the phase transition "ordering-phase separation", i.e. it can be represented in the phase diagram in the form of a narrow band of temperatures parallel to the abscissa axis. For example, in the diagram of Fe-Cr ( Figure 4), the width of such a band at low-temperature phase transition "ordering-phase separation" is very small—we have defined it as equal to $\pm 10^{\circ} \mathrm{C}$ [17].

The method of XPS was used to determine the sign of the chemical interaction energy in the systems Fe-Co [9], Ni-Mo [42], Co-Mo [43], Ni-Co [10] at different temperatures. Here is an example of its use in the study of the $\mathrm{Co}_{3} \mathrm{Ni}$ alloy. X-ray photoelectron spectra were obtained from the $\mathrm{Co}_{73} \mathrm{Ni}_{27}$ alloy at the following temperatures of specimen heating: $200^{\circ} \mathrm{C}, 500^{\circ} \mathrm{C}, 800^{\circ} \mathrm{C}$ and $1100^{\circ} \mathrm{C}$. Figure 7 shows the valence band spectra obtained at these temperatures, as well as reference spectra of pure Co and $\mathrm{Ni}$ (at room temperature) [10]. At temperatures of $200^{\circ} \mathrm{C}$ and $500^{\circ} \mathrm{C}$, the valence band spectra of the alloy have a double band structure due to a small overlap of the d-bands of $\mathrm{Co}$ and $\mathrm{Ni}$ atoms, which are characteristic of the ordered state, when unlike atoms are in the immediate environment. At temperatures of $800^{\circ} \mathrm{C}$ and $1100^{\circ} \mathrm{C}$, the spectra of the valence bands of the alloy have the form of a superposition of the valence bands of the components, which are characteristic of the phase separation tendency, when the same atoms are in the immediate environment.

The results obtained by the method of X-ray photoelectron spectroscopy allow concluding that the current concept (the sign of the deviations from ideality is one and the same for all heating temperatures of this or that alloy) has to be abandoned. It has been shown that in alloys of many systems, at a temperature specific for each system, the sign of the energy of chemical interaction can change [9] [42] [43].

\section{Survey of Recent Advances in the Study of the Transition "Ordering-Phase Separation"}

Phase transition "ordering-phase separation" was first experimentally discovered in alloys of the Fe-Cr system [8]. In the following few years, using TEM and XPS methods it was found in alloys of another 14 of 15 binary 


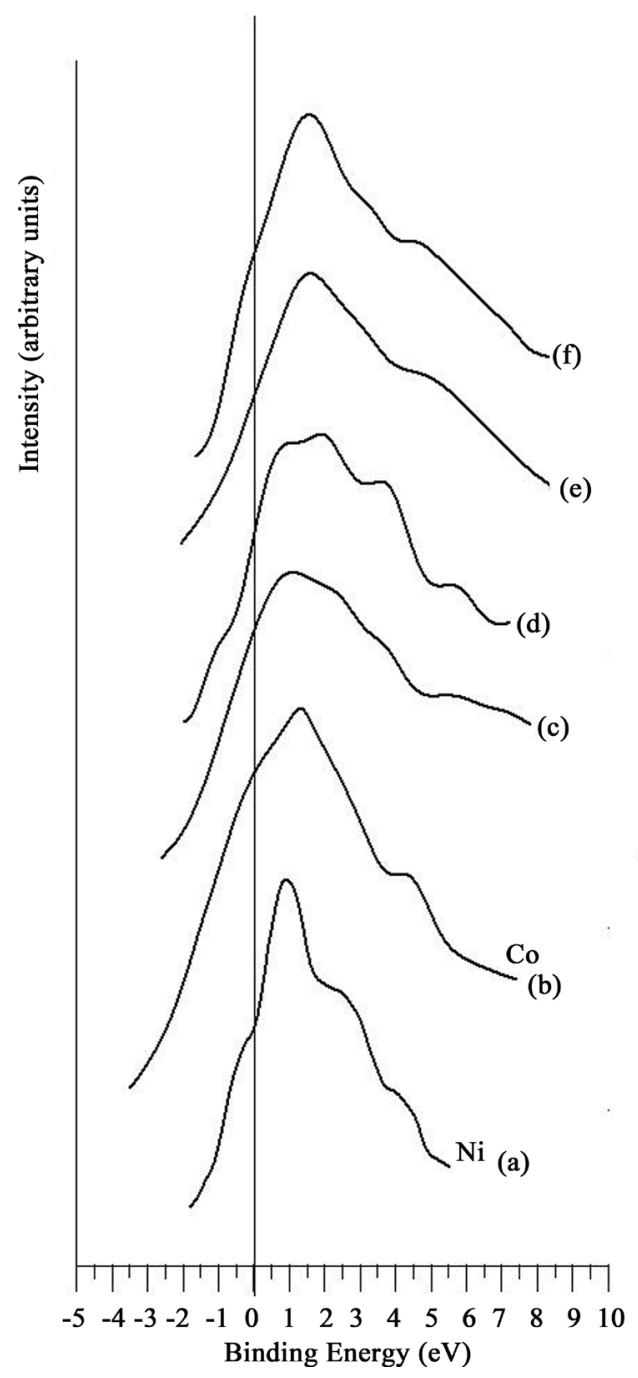

Figure 7. $\mathrm{Co}_{3} \mathrm{Ni}$ alloy. Photoelectron spectra of the 3d-valence band. Reference spectra: (a) $\mathrm{Ni}$ (b) Co. Experimental spectra obtained at 200 (c), 500 (d), 800 (e) and $1100^{\circ} \mathrm{C}$ (f).

systems studied. This transition occurs at a temperature, specific for each system, when the sign of the chemical interaction between atoms of A and B is reversed. The transition occurs at the level of changes in the electronic structure of the alloy (the shape of the valence band determined by XPS changes). The change of the sign of the chemical interaction energy between component atoms reverses the direction of diffusion fluxes in the alloy, which affects changes in the type of microstructures. However, in all studied alloys, where such a transition has been detected, structural changes are characterized by great diversity. Let us consider some of them.

\subsection{Alloys of the Ni-Mo System}

Most interesting structural changes are observed in alloys whose composition corresponds to the left part of the $\mathrm{Ni}-\mathrm{Mo}$ phase diagram [15] (compositions from $\mathrm{Ni}_{2} \mathrm{Mo}$ to $\mathrm{Ni}_{4} \mathrm{Mo}$ ). Structural changes taking place in these alloys during heat treatment have remained unexplained for almost 50 years. In many works it was found that quenching of such alloys from high temperatures (above $1000^{\circ} \mathrm{C}$ ) led to appearance of a system of diffraction maxima at $\{11 / 20\}$ positions in electron diffraction patterns. The diffraction maxima at $\{11 / 20\}$ positions do not correspond to the superlattice reflections of any of the three chemical compounds $\left(\mathrm{Ni}_{2} \mathrm{Mo}, \mathrm{Ni}_{3} \mathrm{Mo}\right.$ and $\left.\mathrm{Ni}_{4} \mathrm{Mo}\right)$ precipitating at lower temperatures. It means that the appearance of such maxima cannot be considered as a certain initial stage of the formation of such compounds. It seems obvious that if quenching is conducted from the solid solution region, then, in the Ni-25 at\% Mo and Ni-20 at\% Mo alloys, the solid solution structure should be fixed. 
It would mean that no additional reflections could be observed in electron diffraction patterns except for the fundamental reflections from the solid solution. In some studies [2] [44]-[47] they have already expressed doubts about the fact that the diffraction maxima at $\left\{\begin{array}{lll}1 & 1 / 2 & 0\end{array}\right\}$ positions not matching the $\mathrm{D} 1_{a}$ and $\mathrm{D} 0_{22}$ reflections of the long-range order can hardly be considered as being related to with the short-range ordering stage of these structures [44]. To explain the situation, some authors have suggested, that at the stage, when the diffraction maxima at $\{11 / 20\}$ positions appear, certain clusters are formed, which do not possess all the symmetry elements of the corresponding long range order structures, and therefore, these clusters cannot be considered as nuclei of long range order phases [45].

Comparison of the results obtained in Refs. [44]-[47] allowed the authors [42] to suggest that in the discussed Mo-Ni alloy system, they most likely deal not with two kinds of order differing in the completeness of the ordered arrangement of atoms in the lattice (i.e. with a long-range or a short-range order) but with two kinds of order differing in the sign of the chemical interaction between the component atoms (i.e. with ordering or phase separation). Therefore, the authors [42] supposed, that the diffraction maxima at $\left\{\begin{array}{lll}1 & 1 / 2 & 0\end{array}\right\}$ positions, found in the electron diffraction patterns of Ni-Mo alloys after their high-temperature quenching as a result of the short-range order formation, in reality appear as the consequence of the process of phase separation taking place in the alloys at high temperatures.

Researchers who encountered the problem of casting liquid Ni-20 at\% Mo and Ni-25 at\% Mo alloys into molds, found the very low castability of these alloys (even at temperatures exceeding the liquidus temperature by $200^{\circ} \mathrm{C}$ ) to be very surprising. This suggested that a precipitation of solid particles consisting of atoms of the much more high-melting Mo takes place at a temperature above the liquidus line indicated in the Mo-Ni phase diagram. To check this suggestion, the $\mathrm{Ni}_{4} \mathrm{Mo}$ alloy was quenched [42]) from the liquid state $\left(1600^{\circ} \mathrm{C}\right)$ directly into ice water [42]. The obtained electron diffraction pattern was absolutely similar to the one shown in Figure 8. In this case, the system of diffraction maxima at $\left\{\begin{array}{lll}1 & 1 / 2 & 0\end{array}\right.$ positions on the electron diffraction pattern of quenched alloys should not be considered as the result of "short-range order" but as the consequence of the precipitation of highly-dispersed solid particles of Mo atoms in the liquid solution. Such precipitation, according to the authors [42], can take place due to the existence of the tendency to phase separation in alloys of the Mo-Ni system at high temperatures including the liquid state.

As was shown [42], heat treatment of the Ni-20 at $\%$ Mo and Ni-25 at $\%$ Mo alloys at $700^{\circ} \mathrm{C}-900^{\circ} \mathrm{C}$ leads to disappearance of the system of diffraction maxima at $\left\{\begin{array}{lll}1 & 1 / 2 & 0\end{array}\right\}$ positions. In the Ni-20 at\% Mo alloy, a system of superlattice reflections (Figure 9(a)) is observed. This system is characteristic of the $\mathrm{Ni}_{4} \mathrm{Mo}$ chemical compound with the $\mathrm{D} 1_{a}$ structure. An electron micrograph of the microstructure is shown in Figure 9(b). It has been concluded that the $\mathrm{D} 1_{a}$ phase particles are rods, whose cross section is close to square [42].

Thus, the discovery of a phase transition "ordering-phase separation" in the Ni-20 at\% Mo and Ni-25 at\% Mo alloys and determination of the temperature of the transition allowed the authors [42] to find out why after a heat treatment at high temperatures, the diffraction maxima at $\left\{\begin{array}{lll}1 & 1 / 2 & 0\end{array}\right\}$ positions appear in the electron diffraction patterns of these alloys, why these maxima do not coincide with the superlattice reflections of the $\mathrm{Ni}_{3} \mathrm{Mo}$

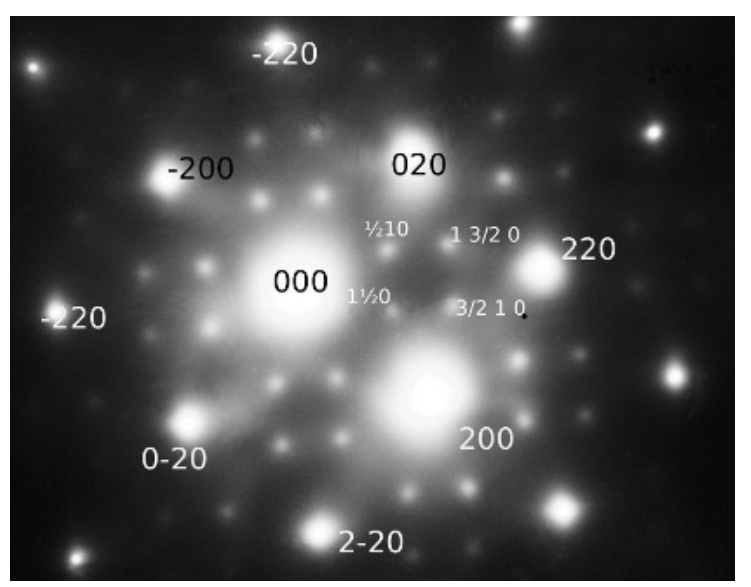

Figure 8. Ni-25 at\% Mo alloy as-quenched from $1300^{\circ} \mathrm{C}$. Electron diffraction pattern, [001] zone axis. The diffraction maxima at $\{11 / 20\}$ positions are shown in the top right corner of the electron diffraction pattern. 


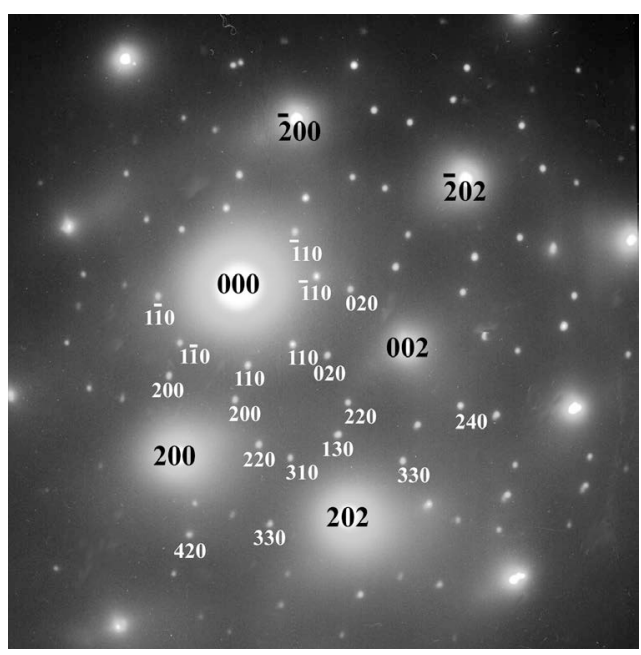

(a)

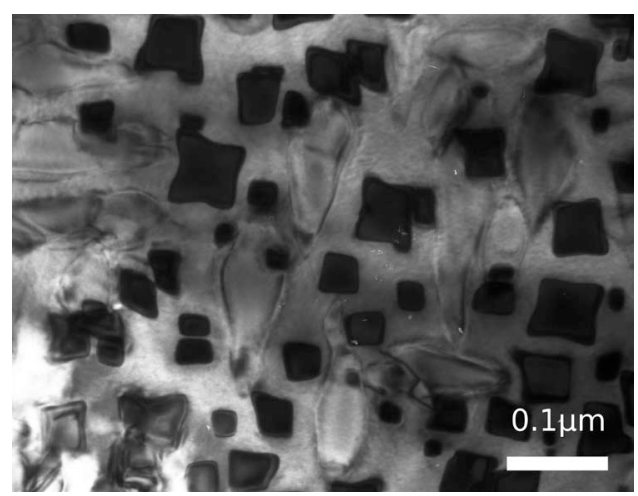

(b)

Figure 9. Ni-20 at\% Mo alloy as-quenched from $800^{\circ} \mathrm{C}$ : (a) electron diffraction pattern, [001] zone axis; (b) bright-field micrograph.

$\left(\mathrm{DO}_{22}\right)$ and $\mathrm{Ni}_{4} \mathrm{Mo}\left(\mathrm{D} 1_{a}\right)$ phases, and why in the Ni-25 at\% Mo alloy, instead of $\mathrm{Ni}_{3} \mathrm{Mo}\left(\mathrm{D0}_{22}\right)$ phase precipitates we find a mixture of particles of two phases- $\mathrm{Ni}_{4} \mathrm{Mo}\left(\mathrm{D} 1_{a}\right)$ and $\mathrm{Ni}_{2} \mathrm{Mo}\left(\mathrm{Pt}_{2} \mathrm{Mo}\right)$.

\section{2. $\mathrm{Ni}_{88} \mathrm{Al}_{12}$ Alloy}

A detailed structural study of the Ni-12 at\% A1 alloy was carried out in Ref. [48]. Figure 10(a) shows an electron diffraction pattern of the studied alloy, water-quenched from $1300^{\circ} \mathrm{C}$ for $1 \mathrm{~h}$. To a certain extent, the intensity and sharpness of the satellite reflections in the electron diffraction pattern, depend on the deflection of foil orientation from the [001] zone axis. When the deflection is considerable, the intensity of fundamental and satellite reflections is almost the same (Figure 10(a)) [48]. The presence of such satellites in the electron diffraction pattern of a binary alloy, the components atoms of which crystallize in the same lattice type, usually indicates the formation of two solid solutions with different lattice parameters, namely, enriched and depleted in the alloying element, i.e. it means that a phase separation occurs in the solid solution.

Besides the above-mentioned system of satellites, one more system of diffraction maxima at $\left\{\begin{array}{llll}1 & 1 / 2 & 0\end{array}\right.$ positions was observed in the electron diffraction patterns in Figure 10(a). As was shown in section 3.1, electron diffraction patterns, obtained from the Ni-20 at\% Mo and Ni-25 at\% Mo alloys in the as-quenched from high temperatures state, give the system of extra reflections at positions $\left\{\begin{array}{lll}1 & 1 / 2 & 0\end{array}\right\}$. At the same time, these alloys have a positive sign of the chemical interaction energy (evaluated by XPS method). After quenching from $1200^{\circ} \mathrm{C}$, no satellites are observed in the electron diffraction patterns and the microstructure is a solid solution [48]. One can therefore assume that in the studied alloy, at a temperature slightly higher than $1200^{\circ} \mathrm{C}$, the sign of the chemical interaction energy changes and therefore, at $1200^{\circ} \mathrm{C}$ and lower temperatures, a microstructure typ- 
ical of the tendency to ordering should form.

Figure 10(b) shows an electron diffraction pattern of the alloy after aging at $700^{\circ} \mathrm{C}$ for $24 \mathrm{~h}$. This pattern was interpreted as belonging to the $\mathrm{Ni}_{3} \mathrm{Al}$ phase [48]. It means that at $700^{\circ} \mathrm{C}$, the tendency to ordering exists in the alloy. A dark-field image using a $\mathrm{Ni}_{3} \mathrm{Al}$ superlattice reflection (100) shows that the shape of the precipitates is close to cubic (Figure 10(c)).

\section{3. $\mathrm{Co}_{70} \mathrm{Mo}_{30}$ Alloy}

As was detected, the $\mathrm{Co}_{70} \mathrm{Mo}_{30}$ alloy has a sufficiently high hardness after any heat treatment. For example, hardness of the alloy after quenching from liquid state is about $850 \mathrm{HV}$, after quenching from $1200^{\circ} \mathrm{C}-790 \mathrm{HV}$. Following $800^{\circ} \mathrm{C}$ aging up to $50 \mathrm{~h}$ gradually decreases hardness from 790 to $700 \mathrm{HV}$. That high level of hardness after any heat treatment is attributable to the fact that the $\mathrm{Co}_{3} \mathrm{Mo}$ (A3) chemical compound forming at temperatures below $1045^{\circ} \mathrm{C}$ strengthens the alloy either at the cost of its own high hardness (when most part of the matrix is transformed into $\mathrm{Co}_{3} \mathrm{Mo}$ ), or through distortion of the matrix structure due to precipitation of coherent fine-dispersed $\mathrm{Co}_{3}$ Mo phase particles on the slip planes.

The tendency toward phase separation revealed with the help of the XPS method allowed authors [43] to conclude that at temperatures below $1335^{\circ} \mathrm{C}$, phase separation into Mo-enriched and Mo-depleted clusters takes place in the alloy under study. Electron-microscopic study of the alloy in quenched state from temperatures $800^{\circ} \mathrm{C}, 1200^{\circ} \mathrm{C}$ and $1300^{\circ} \mathrm{C}$ showed that in all of the cases, the microstructure of the alloy is the same and represents a uninterrupted periodic alternation of rounded light-color clusters (about $10-15 \mathrm{~nm}$ in diameter), separated by dark diffuse boundaries (Figure 11) [43]. This microstructure resembles an "unfinished" (lacking sharpness) cellular structure, and therefore, for short, it can be called a "quasi-cellular structure" [43]. The ratio of the total areas occupied by light rounded clusters and dark boundaries in the micrographs, which we estimate as 3:7, allowed authors [43] to assume that the first are clusters enriched in Mo and the second are clusters enriched in Co. This quasi-cellular structure is often superposed by strain contrast usually arising at allotropic and martensitic phase transitions. In the selected area electron-diffraction patterns obtained from such a structure, only the fundamental reflections are observed. They testify that the lattice type inside and outside of the cellular is the same.

At quenching from the liquid state $\left(1450^{\circ} \mathrm{C}\right)$ a solid solution structure without any trace of strain contrast is observed, with only stacking faults present [43]. The hardness of the alloy has high values (about $850 \mathrm{HV}$ ). This can mean that the phase transition $\alpha$-Co $\rightarrow \varepsilon$-Co is not the reason for the high hardness of the $\mathrm{Co}_{70} \mathrm{Mo}_{30}$ alloy. The reason seems to lie in the fact, that taking part in the formation of Mo-enriched clusters inside the $\alpha$-Co lattice, the atoms of Mo, whose size is 7\% larger than those of Co, significantly distort the lattice in the whole volume of the alloy. Such distortion of the lattice is also preserved at all the temperatures studied up to the solidus temperature. We can assume that this is the true cause of the high hardness of the investigated alloy. Thus, in alloys similar in composition to the investigated alloy, at lowering the temperature from the solidus, there occurs decomposition of the liquid solution into clusters strongly enriched in Mo and Co (a quasi-cellular structure is formed).

As a result of such a phase separation and formation of clusters strongly enriched in Co or Mo, at aging temperatures, the allotropic phase transition $\alpha$-Co $\rightarrow \varepsilon$-Co occurs in the Co-enriched clusters and it extends to the whole volume of the alloy. In contrast to Ni-based superalloys, in which the high phase and structural stability is achieved due to formation of geometrically close-packed intermetallic phases which occurs at high temperatures, in Co-Mo superalloys, such stability is achieved due to deep decomposition of the liquid solution to form a high-dispersity microstructure.

\subsection{Alloys of the Ni-Co System}

The phase diagram of the Ni-Co system is characterized by great simplicity: for all compositions, at all temperatures only the solid solution is shown in the diagram [15]. No phase transformations except the allotropic $\alpha$-Co $\rightarrow \varepsilon$-Co (at $422^{\circ} \mathrm{C}$ ) occur in the system [15]. Apparently, this is why the literature on structural transformations in the alloys of this system is extremely scarce.

The sign of the chemical interaction energy in the alloys of the system was determined by the method of XPS, at the following temperatures of specimen heating: $200^{\circ} \mathrm{C}, 500^{\circ} \mathrm{C}, 800^{\circ} \mathrm{C}$ and $1100^{\circ} \mathrm{C}$ [10]. The results are presented in section 2.3 (Figure 7) of the present article. The temperature of the transition "ordering-phase separa- 


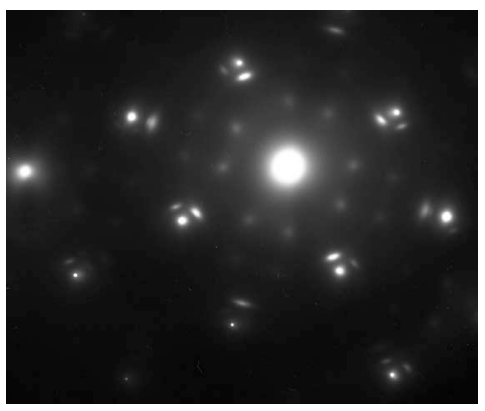

(a)

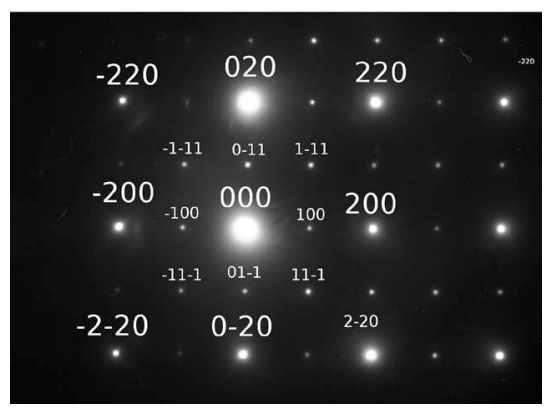

(b)

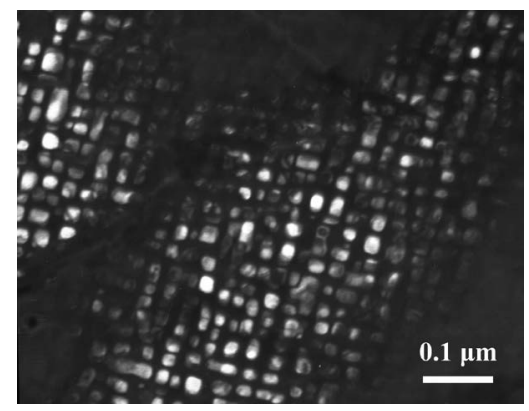

(c)

Figure 10. Ni-12 at\% A1 alloy. Water-quenching from (a) $1300^{\circ} \mathrm{C}$ for $1 \mathrm{~h}$ : electron diffraction pattern; the foil orientation is some deflected from [001] zone axis; (b) $1200^{\circ} \mathrm{C}$ for $1 \mathrm{~h}$, electron diffraction pattern; (c) the same, dark-field micrograph using a $(-100)$ superlattice spot from (b).

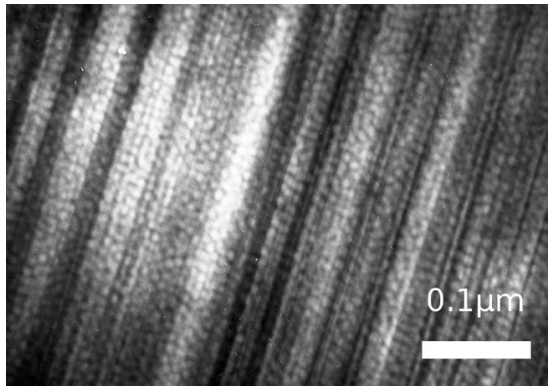

Figure 11. $\mathrm{Co}_{70} \mathrm{Mo}_{30}$ alloy water-quenched from $1300^{\circ} \mathrm{C}$. Bright-field micrograph.

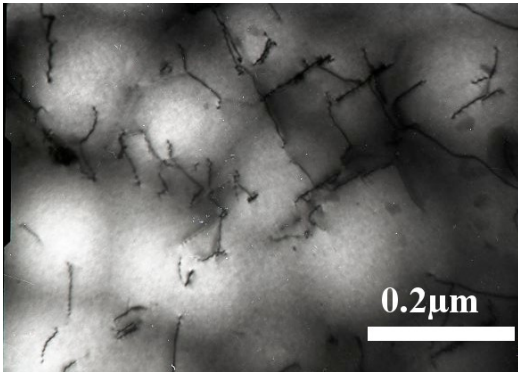

(a)

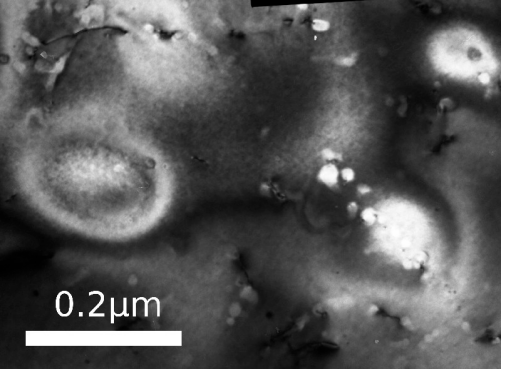

(b)

Figure 12. $\mathrm{Ni}_{73} \mathrm{Co}_{27}$ alloy. Microstructure (a) after water-quenching from $1200^{\circ} \mathrm{C}$ (absorption contrast) and (b) after aging at $500^{\circ} \mathrm{C}$ for $10 \mathrm{~h}$.

tion” was determined by XPS as being in the range of $500^{\circ} \mathrm{C}-800^{\circ} \mathrm{C}$ [10]. The microstructure of the $\mathrm{Ni}_{73} \mathrm{Co}_{27}$ alloy, exposed for $1 \mathrm{~h}$ at $1200^{\circ} \mathrm{C}$ is shown in Figure 12(a). Round light spots with diffuse edges are observed on a dark background. It is obvious that formation of these clusters occurs without significant changes in the parameter of the lattice, i.e. changes that could lead to the appearance of the diffraction contrast. A similar structure is observed after subsequent aging of the alloy at $800^{\circ} \mathrm{C}$ and $600^{\circ} \mathrm{C}$ [10]. The cause for the formation of such clusters of cobalt atoms becomes clear if the electron microscopic data is compared with the results obtained by the method of XPS [10].

The lowest temperature of heat treatment, after which, in some parts of the foil it is still possible to detect such clusters, is $500^{\circ} \mathrm{C}$. Simultaneously with dissolution of large clusters, detectable due to absorption contrast the smaller light particles are formed. They become to be visible thanks to diffraction contrast. Figure 12(b) shows the microstructure of the alloy after aging at $500^{\circ} \mathrm{C}$ for $10 \mathrm{~h}$. Comparison of the microstructure images after aging at $500^{\circ} \mathrm{C}$ for different periods of time lead to the conclusion that the transition from larger clusters to smaller particles occurs gradually, through simultaneous dissolution of large clusters and formation of small 
particles both at the defects of the crystal structure and in defect-free areas of the matrix, including the locations of the dissolving large clusters.

\subsection{Alloys of the Ni-Cr System}

It was believed earlier that each system has its own transition temperature, which is the same for all alloys of this system. Therefore, they believed that to determine the temperature of such a phase transition it was sufficient to take only one of any alloys of this system and to investigate it. Indeed, for a number of systems in which two or more compositions were studied (for example, $\mathrm{Fe}_{80} \mathrm{Cr}_{20}, \mathrm{Fe}_{70} \mathrm{Cr}_{30}, \mathrm{Fe}_{60} \mathrm{Cr}_{40}, \mathrm{Fe}_{50} \mathrm{Cr}_{50}$ [17]; $\mathrm{Fe}_{68} \mathrm{Ni}_{32}$, $\mathrm{Fe}_{23} \mathrm{Ni}_{77}$ [49]; $\mathrm{Ni}_{3} \mathrm{Mo}, \mathrm{Ni}_{4} \mathrm{Mo}$ [42]), the temperature of the phase transition "ordering-phase separation", for all compositions studied, was the same.

However, there exists one system which differs from other systems in the fact that in it, the phase transition "ordering-phase separation" occurs as a result of a change in concentration, not a change in the temperature of the alloy. This is the Ni-Cr system [50]. It was found [50], that in this system, the sign of the chemical interaction energy of the $\mathrm{Ni}_{40} \mathrm{Cr}_{60}$ and $\mathrm{Ni}_{68} \mathrm{Cr}_{32}$ alloys was different in the entire temperature range of their heating. Such a change in the type of the chemical bonding between dissimilar atoms, which occurs in dependence upon the change of the concentration of alloys, does not yet have any reasonable explanation.

Two alloys were studied: the $\mathrm{Ni}_{40} \mathrm{Cr}_{60}$ and $\mathrm{Ni}_{68} \mathrm{Cr}_{32}$ alloy [50]. According to the existing phase diagram of $\mathrm{Ni}-\mathrm{Cr}$ [15], at compositions close to the $\mathrm{Ni}_{40} \mathrm{Cr}_{60}$ alloy, a eutectic is formed in the $\mathrm{Ni}-\mathrm{Cr}$ system. This could mean that in alloys of such a composition there is bound to be a tendency to phase separation. However, over the entire temperature range of the study, from the liquid state of this alloy to $550^{\circ} \mathrm{C}$, only microstructures corresponding to the tendency to ordering were found experimentally. This conclusion follows from Figure 13, which presents a bright-field image and an electron diffraction pattern obtained from a specimen as-quenched from the liquid $\left(1450^{\circ} \mathrm{C}\right)$ state.

The microstructure in Figure 13(a) consists of relatively large grains of an elongated shape, randomly arranged in the solid solution. A dislocation network is visible along the boundaries of the grains. An electron diffraction pattern, obtained from these grains (Figure 13(b)), indicates that they have an orthorhombic lattice of the $\mathrm{Pt}_{2} \mathrm{Mo}$ type, characteristic of the $\mathrm{Ni}_{2} \mathrm{Cr}$ chemical compound. However, according to the existing phase diagram of Ni-Cr, such a compound is formed only at temperatures below $590^{\circ} \mathrm{C}$. Formation of the $\mathrm{Ni}_{2} \mathrm{Cr}$ chemical compound in the liquid solution means that the $\mathrm{Ni}_{40} \mathrm{Cr}_{60}$ alloy, at $1450^{\circ} \mathrm{C}$, has a very strong tendency to ordering. Thus, the process of solidification of the $\mathrm{Ni}_{40} \mathrm{Cr}_{60}$ alloy begins not with the formation of an eutectic consisting of nickel and chromium grains (as it follows from the diagram), but with a formation of grains of the $\mathrm{Ni}_{2} \mathrm{Cr}$ chemical compound with an orthorhombic lattice of the $\mathrm{Pt}_{2} \mathrm{Mo}$ type.

Microstructure of the $\mathrm{Ni}_{40} \mathrm{Cr}_{60}$ alloy after aging at $550^{\circ} \mathrm{C}$ is shown in Figure 14(a). The electron diffraction pattern shows that these particles are the $\mathrm{Ni}_{2} \mathrm{Cr}$ chemical compound (Figure 14(b)). Comparing Figure 13 and Figure 14, we can conclude that in both cases, differences are observed only in the dispersity of the precipitates.

Quenching of the $\mathrm{Ni}_{68} \mathrm{Cr}_{32}$ alloy from the liquid state $\left(1450^{\circ} \mathrm{C}\right)$ leads to the formation of the structure shown in Figure 15(a). Round dark spots with diffuse edges are observed in the image. The authors of Ref. [50] considered them as clusters of chromium atoms in the nickel lattice. Apparently, the high level of the energy of the chemical interaction between atoms of $\mathrm{Ni}$ and $\mathrm{Cr}$, however, already of the opposite (positive) sign takes place in the $\mathrm{Ni}_{68} \mathrm{Cr}_{32}$ alloy at high temperatures. A similar structure of chromium atom clusters was observed in electron microscope images also after quenching the alloy from 1200, 1000, 800 as well as from $550^{\circ} \mathrm{C}$ (Figure 15(b)).

Thus, experimental results [50] have been obtained, indicating that the signs of the chemical interaction between component atoms in the $\mathrm{Ni}_{40} \mathrm{Cr}_{60}$ and $\mathrm{Ni}_{68} \mathrm{Cr}_{32}$ alloys are constant over the entire temperature range of their heating, only in the $\mathrm{Ni}_{40} \mathrm{Cr}_{60}$ alloy this sign is negative and in the $\mathrm{Ni}_{68} \mathrm{Cr}_{32}$ alloy it is positive. This means that the boundary between the areas of ordering and phase separation in the phase diagram of Ni-Cr should be located between these two compositions and should be to a greater extent depend on the change in the concentration than on the change in the temperature. Therefore, the aim of the subsequent study was to determine the position of this boundary in coordinates temperature-composition. The $\mathrm{Ni}_{46} \mathrm{Cr}_{54}$ (№3), $\mathrm{Ni}_{56} \mathrm{Cr}_{44}$ (№4) and $\mathrm{Ni}_{62} \mathrm{Cr}_{38}$ (№5) alloys, the compositions of which are within the range of concentrations of previously studied $\mathrm{Ni}_{40} \mathrm{Cr}_{60}$ (№2) and $\mathrm{Ni}_{68} \mathrm{Cr}_{32}$ (№1)alloys, were chosen for the study.

Using the existing phase diagram of Ni-Cr, all the microstructure data for alloys №1-5 have been plotted for various heat treatment temperatures (Figure 16) [51]. A dashed line between the $\bullet$ and $\boldsymbol{\Delta}$ points in the phase 


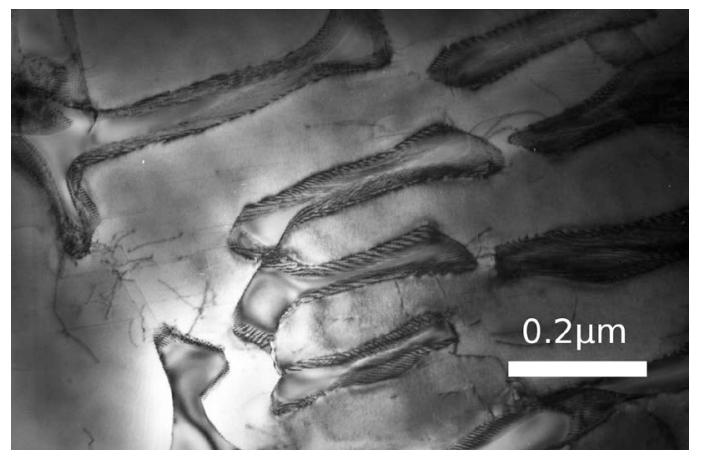

(a)

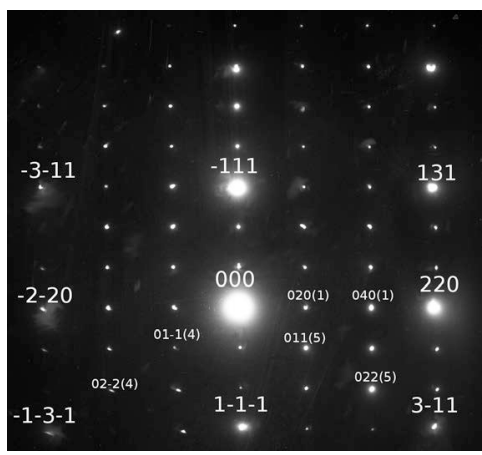

(b)

Figure 13. $\mathrm{Ni}_{40} \mathrm{Cr}_{60}$ alloy. Quenching from the liquid state $\left(1450^{\circ} \mathrm{C}\right)$. (a) Bright-field image of the microstructure; (b) electron diffraction pattern, [1]-[12] zone axis; orientation relationship: $\{112\}_{M} / /\{102\}_{\mathrm{Cr} 2 \mathrm{Ni}}$; superlattice reflections from variants (1), (4), (5) are given in orthorhombic indices; fundamental reflections are given in cubic indices.

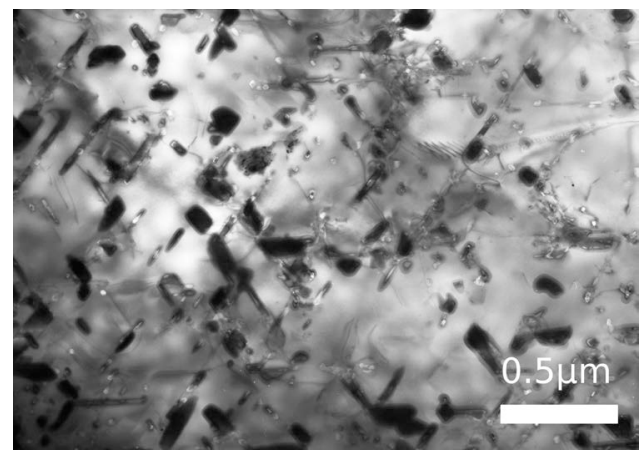

(a)

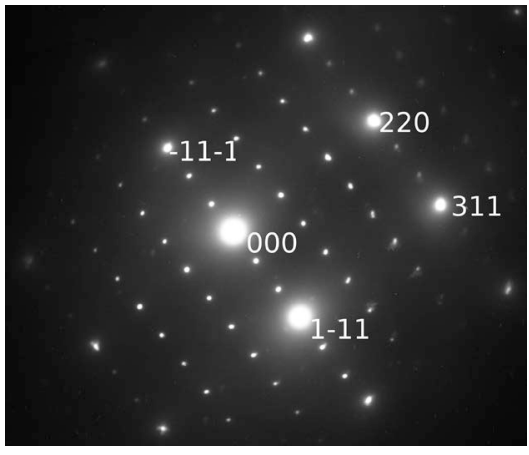

(b)

Figure 14. $\mathrm{Ni}_{40} \mathrm{Cr}_{60}$ alloy. Aging at $550^{\circ} \mathrm{C}$. (a) Bright-field image of the microstructure; (b) electron diffraction pattern, [1]-[12] zone axis.

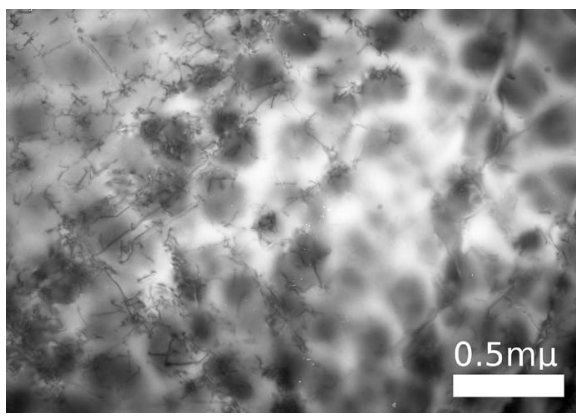

(a)

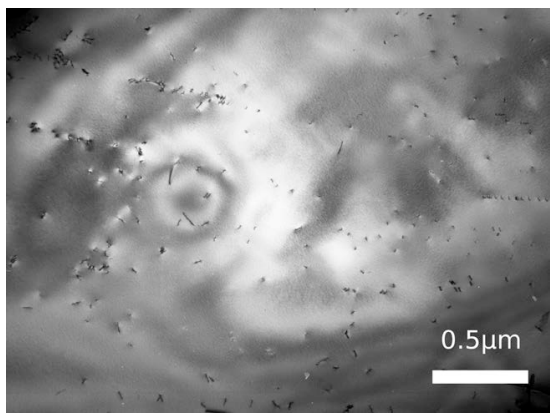

(b)

Figure 15. $\mathrm{Ni}_{68} \mathrm{Cr}_{32}$ alloy. Bright-field image of the microstructure after water-quenching from liquid state (a) and aging at $550^{\circ} \mathrm{C}$ (b). Absorption contrast.

diagram has been drawn. Such a dashed line can be regarded as the line of the phase transition "ordering-phase separation". As can be seen, its position in the diagram in a greater degree depends on the concentration of the alloy than on the heat-treatment temperature [51]. The causes for emergence of such a situation, when the sign of the energy of the chemical interaction between the component atoms depends mainly on the composition of the alloy, are not yet clear.

\section{6. $\mathrm{Ni}_{75} \mathrm{~V}_{25}$ Alloy}

A great number of experimental works, for example, [52]-[54], have been devoted to the investigation of phase 


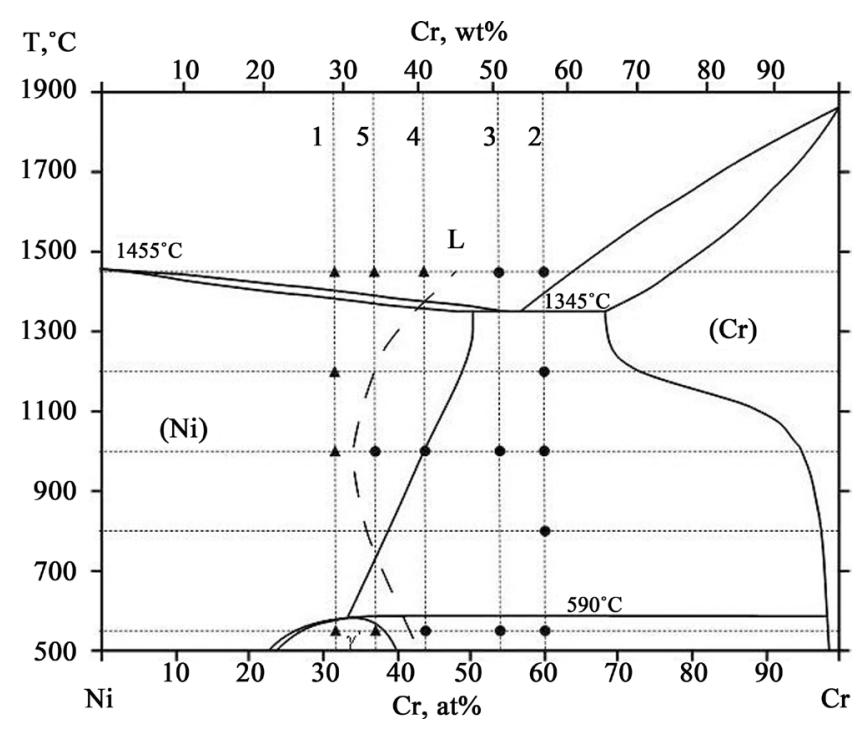

Figure 16. Ni-Cr phase diagram. Compositions of alloys studied are pointed out in the diagram by the vertical lines and numerous. Symbols: $\bullet=$ ordering microstructure; $\boldsymbol{\Delta}=$ phase separation one.

transitions in the Ni-25 at\% $\mathrm{V}$ alloy due to very interesting and hard-to-explain structural changes observed in the alloy after various heat treatments.

At present, few authors dispute the generally accepted opinion, that at $1045^{\circ} \mathrm{C}$, the disordered Ni-V solid solution undergoes an ordering transformation to form a stoichiometric ordered $\mathrm{Ni}_{3} \mathrm{~V}$ phase [52]-[54]. The crystal structure of the ordered $\mathrm{Ni}_{3} \mathrm{~V}$ phase consists of tetragonal $\mathrm{D} 0_{22}$ unit cells. The correlation of the fcc and $\mathrm{DO}_{22}$ lattices allows the formation of three variants of unit cell packing, and in each of the variants, the $c$ ' axis of the phase lattice should be oriented along one of the three $a$-axes of the lattice of the disordered fcc solution [52]. It is believed that in the process of water quenching (the rate of cooling can reach about $10^{5}{ }^{\circ} \mathrm{C} / \mathrm{s}$ ) from high temperatures, this very three-variant long-range order forms in the $\mathrm{Ni}-25$ at\% $\mathrm{V}$ alloy. As it was shown [52] [54], the kinetics of the ordering reaction in the stoichiometric $\mathrm{Ni}_{75} \mathrm{~V}_{25}$ alloy is very fast and cannot be fully suppressed by brine quenching even in the "as-melt-spun" condition. At the same time, many authors [52]-[54] think that the long-range order $\mathrm{D}_{22}$ structure is formed during the straight phase transition $\mathrm{Al} \rightarrow \mathrm{D}_{22}$ which takes place during quenching the alloy in water when the alloy temperature passes through the point of $1045^{\circ} \mathrm{C}$. How such phase transition occurs and how the three-variant structure of the $\mathrm{D}_{22}$ phase is formed within the crystal lattice of the A1 solid solution during such a short period is not explained.

During the phase transition $\mathrm{A} 1 \rightarrow \mathrm{D}_{22}$, which is believed to take place at $1045^{\circ} \mathrm{C}$, the redistribution of $\mathrm{V}$ atoms on the lattice sites (from statistical to ordered state) can occur only by diffusion, which requires quite a definite time. Even more time is necessary to orient the unit cells of the $\mathrm{D}_{22}$ phase so that the $c^{\prime}$ axes of the $\mathrm{D}_{22}$ phase were located along each of the three mutually perpendicular axes of the disordered fcc solid solution. It is precisely this arrangement of the unit cells of the $\mathrm{D}_{22}$ phase in the alloy that provides the formation of the three-variant ordered structure with a characteristic arrangement of extra reflections in the electron diffraction patterns. In this case, it should be noted that if the formation of the $\mathrm{D}_{22}$ phase with the three-variant packing of unit cells occurred in the solid solution, it would necessarily lead to a growth of elastic stresses both inside the $\mathrm{D}_{22}$ phase and inside the solid solution, which, in its turn, would be reflected in the electron diffraction pattern in the form of various distortions in the shape and arrangement of the reflections. As it is shown in Refs [52]-[54], no distortions of the kind are observed in the electron diffraction patterns.

As it has already been mentioned, it is believed that the $\mathrm{A} 1 \rightarrow \mathrm{D} 0_{22}$ phase transition taking place at $1045^{\circ} \mathrm{C}$ cannot be suppressed by any of the quenching methods [52]-[54] although the cooling rate of, for example, thin specimens, even at conventional water quenching is very high and can approach to $10^{5}{ }^{\circ} \mathrm{C} / \mathrm{s}$. It is obvious, that at such a cooling rate, no diffusion phase transitions in $\mathrm{Ni}_{75} \mathrm{~V}_{25}$ alloy have time to happen. This raises the question as to how during quenching from high temperatures (e.g. from $1200^{\circ} \mathrm{C}$ ) atoms of vanadium manage to occupy the sites in the lattice, which lead to the transformation from fcc to $\mathrm{D}_{22}$ at temperatures below $1045^{\circ} \mathrm{C}$.

A reasonable answer to this question can only be obtained if one assumes that the formation of the three-va- 
riant $\mathrm{D}_{22}$ structure takes place during slow cooling of the casting from the liquid state. It is in the liquid solution and at a temperature no lower than the solidus, that all conditions are present for unimpeded formation of the three-variant $\mathrm{D}_{22}$ structure: in the liquid state, the diffusion rate of the component atoms is incomparably higher than in the solid solution, and the formation of the $\mathrm{D}_{22}$ phase and packing of its unit cells in the form of the three-variant structure are not accompanied by the appearance of elastic stresses. If this assumption is true, then it becomes clear why superlattice reflections are quite sharp and intense and why in the electron diffraction patterns there are no distortions that commonly occur with the appearance of elastic stresses in the crystal lattice, which are associated with phase transitions taking place in it.

To check the suggestion concerning the $\mathrm{D}_{22}$ phase formation from the liquid solution, the quenching of the studied alloy was conducted from the liquid $\left(1600^{\circ} \mathrm{C}\right)$ and solid $\left(1200^{\circ} \mathrm{C}\right.$ for $1 \mathrm{~h}$ and $\left.10 \mathrm{~h}\right)$ states [55]. Figure 17(a) presents the selected area electron diffraction pattern of the alloy quenched from the liquid state into ice water. On the electron diffraction pattern, the characteristic system of superlattice reflections from the three-variant structure of the $\mathrm{D}_{22}$ phase and the system of fundamental reflections from the $\mathrm{A} 1$ solid solution are observed. When quenching was conducted from the solid state (from $1200^{\circ} \mathrm{C}$, exposure for $1 \mathrm{~h}$ ), the intensity of the superlattice reflections corresponding to variant III was appreciably weak; but when it was conducted after aging at $1200^{\circ} \mathrm{C}$ for $10 \mathrm{~h}$, these reflections were just absent (Figure 17(b)). This led to the conclusion that the three-variant structure of the $\mathrm{D}_{22}$ phase is formed in the liquid state. If the structure is formed in the liquidus-solidus temperature range, then the remaining portion of the liquid solution crystallizes at the solidus temperature forming the lattice of the A1 solid solution.

If in the $\mathrm{Ni}_{75} \mathrm{~V}_{25}$ alloy the transformation from the three-variant structure to the two-variant structure takes place at a temperature of $1200^{\circ} \mathrm{C}$, then it is possible to expect that further decrease of heat treatment temperature should lead to the formation of the one-variant structure. With this in mind prolonged (up to $84 \mathrm{~h}$ ) heat treatment was conducted at $800^{\circ} \mathrm{C}$ [55]. The microstructure which is formed as a result of the decomposition of the A1 solid solution is very much similar to the morphology of $\mathrm{Ni}_{4} \mathrm{Mo}\left(\mathrm{D} 1_{a}\right)$ phase particles which are formed during the aging of the $\mathrm{Ni}_{80} \mathrm{Mo}_{20}$ alloy, see Figure 9(b). The interpretation of the patterns indicates that these reflection systems are characteristic of the $\mathrm{Ni}_{4} \mathrm{Mo}$ chemical compound with the $\mathrm{D} 1_{a}$ structure. However the lattice parameters of this phase $(a=0.5365 ; c=0.3369 \mathrm{~nm})$ significantly differ from the corresponding parameters of the $\mathrm{D} 1_{a}$ phase in the $\mathrm{Ni}_{80} \mathrm{Mo}_{20}$ alloy. A simple calculation shows that the phase can be considered as belonging to the $\mathrm{D} 1_{a}$ crystal structure with a tetragonal body-centered lattice, i.e. to the $\mathrm{Ni}_{4} \mathrm{~V}$ phase. As it is known, such a phase does not exist in the Ni-V system in the equilibrium state. Therefore, one can assume that it is formed as a metastable intermediate state of the alloy in the process of the rearrangement of the A1 solid solution lattice into the lattice of the $\mathrm{D}_{22}$ phase. Moreover, the $\mathrm{D} 1_{a}$ phase is found only after 84-h aging; after 180-h aging it is not found in the microstructure.

As it was already mentioned in section 3.1, the body-centered tetragonal $\mathrm{D} 1_{a}$ phase is the intermediate link in the transition $\mathrm{A} 1 \rightarrow \mathrm{D0}_{22}$. Therefore, the inflection in the temperature-time curve at $1045^{\circ} \mathrm{C}$, (found previously when constructing the phase diagram of $\mathrm{Ni}-\mathrm{V}$ and interpreted as an evidence of the phase transition $\mathrm{A} 1 \rightarrow \mathrm{D}_{22}$ ) does not appear due to the precipitation of the three-variant $\mathrm{D}_{22}$ phase (as shown above, it is formed when the alloy is in the liquid state), it appears due to the precipitation of an intermediate metastable $\mathrm{Ni}_{4} \mathrm{~V}\left(\mathrm{D} 1_{a}\right)$ phase. In other areas of the foil, the so-called lamellar-like microstructure [55] is observed, inside of which one can see

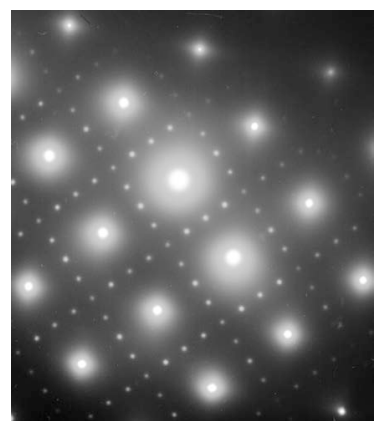

(a)

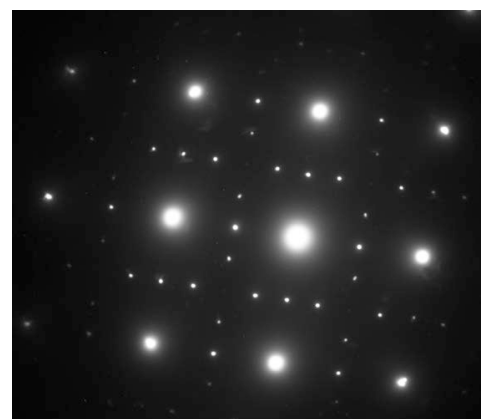

(b)

Figure 17. $\mathrm{Ni}_{75} \mathrm{~V}_{25}$ alloy. Water-quenching from liquid state (a) and from $1200^{\circ} \mathrm{C}$ for $10 \mathrm{~h}$ (b): electron diffraction patterns, [001] zone axis. 
stacking faults. The electron diffraction pattern in Figure 18 shows that this microstructure is nothing but particles of the one-variant $\mathrm{Ni}_{3} \mathrm{~V}\left(\mathrm{DO}_{22}\right)$ phase in an $\mathrm{A} 1$ solid solution.

Further prolonged aging, at $800^{\circ} \mathrm{C}$ for $180 \mathrm{~h}$, leads to full disappearance of $\mathrm{Ni}_{4} \mathrm{~V}\left(\mathrm{D} 1_{a}\right)$ particles and, in some places, disappearance of the A1 solid solution. The electron diffraction pattern demonstrates only a system of fundamental reflections from the one-variant $\mathrm{D}_{22}$ phase. Thus, separation of the structure into the solid solution and the $\mathrm{D}_{22}$ phase with the three-variant packing of cells, which takes place during solidification, leads to the fact, that in the process of relaxation, for example at $800^{\circ} \mathrm{C}$, each of these structures evolves according to its own scenario: the three-variant microstructure of the $\mathrm{D}_{22}$ phase gradually transforms into the one-variant structure, while the solid solution transforms into the equilibrium $\mathrm{D}_{22}$ phase through precipitation of the metastable intermediate $\mathrm{Ni}_{4} \mathrm{~V}\left(\mathrm{D} 1_{a}\right)$ phase. As the end result, the one-variant $\mathrm{Ni}_{3} \mathrm{~V}\left(\mathrm{DO}_{22}\right)$ microstructure will be formed in the whole volume of the alloy [55].

\subsection{Microstructures Responsible for the Emergence of the Invar and Permalloy Effects in Fe-Ni Alloys}

Alloys of the Fe-Ni system play a very important role in modern engineering: iron dominated alloys (invars) have very low values of the linear expansion temperature coefficient; nickel dominated alloys (permalloys) are soft magnetic materials with a very high magnetic permeability. The vast majority of authors [56]-[58], who studied these alloys, explained the emergence of such properties in the Fe-Ni alloys by their structural features, in particular, the formation of a short-range and/or a long-range order, ordering, formation of a modulated structure, etc. These conclusions were based on integral methods of microstructure research (X-ray diffraction, neutron diffraction, Mossbauer spectroscopy, study of changes in the physical properties of the alloys and the like). Direct local electron microscopic methods for studying the microstructure were used rather infrequently and the interpretation of the results, especially in terms of the short- and long-range order did not clarify the general picture of the processes forming such structures, which, in its turn, made it impossible to link specific changes in the properties of alloys with specific changes in their microstructure.

As for the generally accepted phase diagram of $\mathrm{Fe}-\mathrm{Ni}$, two temperature regions are well visible in it-above and below the temperature range of $500^{\circ} \mathrm{C}-600^{\circ} \mathrm{C}$. Below this range, real or hypothetical chemical compounds precipitate in the system [15]. Above it, there exist regions of solid solutions. The presence of a region of the solid solution in the equilibrium phase diagram, which as it is known from thermodynamics, is not an equilibrium phase, indicates rather gaps in our knowledge than the actual structural state of the studied alloy at these temperatures. At the same time, improvement of soft magnetic properties of permalloys and low values of the linear expansion temperature coefficient of invars are usually associated with the formation of a short- or a longrange order in these alloys [56] [58]. What concrete structures are denoted by the abstract terms "short-range order" and "long-range order" is usually not disclosed and no direct experimental evidence is given for the existence of this or that structure responsible for the improvement of the mentioned physical properties of the alloy.

Therefore, of particular interest is to find out which particular type of microstructure is responsible for the appearance of the invar and permalloy effects in alloys of the Fe-Ni system, in order to have a clear idea of the heat treatment needed to obtain the best properties.

X-ray photoelectron spectra obtained on the $\mathrm{Fe}_{68} \mathrm{Ni}_{32}$ alloy at the temperatures of specimen heating $200^{\circ} \mathrm{C}$, $500^{\circ} \mathrm{C}, 800^{\circ} \mathrm{C}$ and $1100^{\circ} \mathrm{C}$ have shown that in the temperature range between $500^{\circ} \mathrm{C}$ and $800^{\circ} \mathrm{C}$, a phase transition 'ordering-phase separation' takes place in the alloy, during which the sign of the ordering energy is reversed [59].

After quenching in water from a temperature of $1300^{\circ} \mathrm{C}$ the structure shown in Figure 19 is formed in many microscopic portions of the $\mathrm{Fe}_{68} \mathrm{Ni}_{32}$ alloy. Round dark spots with diffuse edges and sizes of the order of 0.1 $0.2 \mu \mathrm{m}$ are observed on a bright background, as a result of the electron-microscopic absorption contrast from certain clusters. It is obvious that the formation of these clusters occurs without any significant elastic changes in the lattice, i.e. changes that could lead to the appearance of the diffraction contrast. It should be noted that other components of the contrast that are visible in Figure 19 (extinction contours, dislocations), are formed as a result of the diffraction contrast. The cause for the formation of such clusters of nickel atoms becomes clear if the electron microscopic data is compared with the results obtained by the method of XPS. Such a comparison leads to the conclusion that the formation of the structure shown in Figure 19 is a consequence of the fact that a tendency to phase separation exists in the alloy at $1300^{\circ} \mathrm{C}$. 


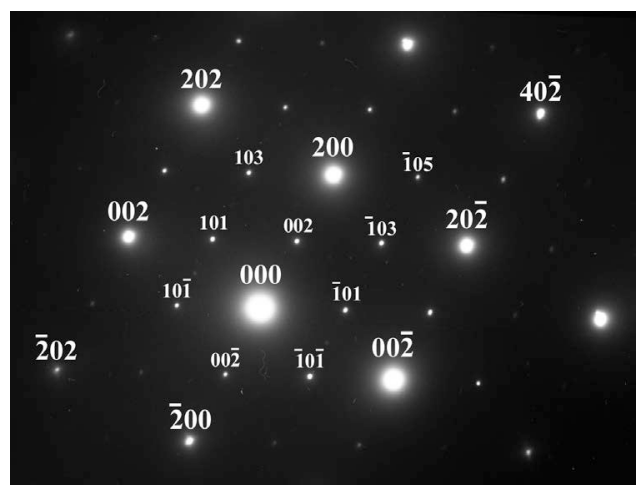

Figure 18. $\mathrm{Ni}_{75} \mathrm{~V}_{25}$ alloy. $800^{\circ} \mathrm{C}$ aging for $84 \mathrm{~h}$, electron diffraction pattern, [001] zone axis.

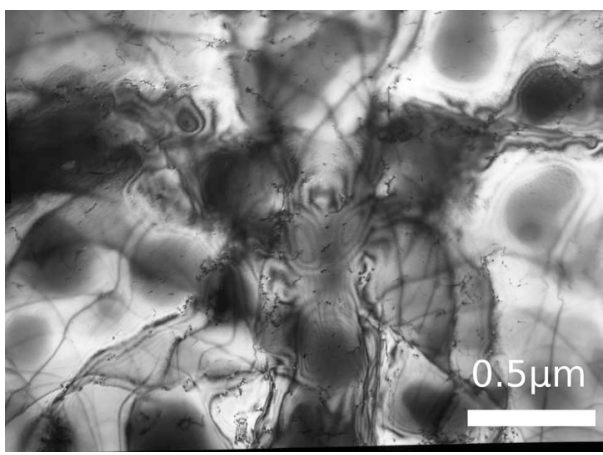

Figure 19. $\mathrm{Fe}_{68} \mathrm{Ni}_{32}$ alloy. Water-quenching from liquid state $\left(1600^{\circ} \mathrm{C}\right)$. Bright-field image of a microstructure.

At lowering the heat treatment temperature to $740^{\circ} \mathrm{C}$, the morphology of clusters in electron microscopic images changes. This seems to be associated with an increase of nickel concentration in nickel-enriched clusters (Figure 20) [59]. A structure very similar to a modulated structure is formed instead of round dark spots. The obtained structural results allow concluding [59] that it is precisely such a fcc structure consisting of nickelenriched and depleted modulations that is responsible for the high invar properties of the alloy, when at a change of the temperature, lattice expansion in modulations of one kind occurs due to lattice compression in modulations of another kind.

Quenching the $\mathrm{Fe}_{23} \mathrm{Ni}_{77}$ alloy from the liquid state (from $1600^{\circ} \mathrm{C}$ ) fixes the phase separation microstructure (Figure 21) similar to that shown in Figure 19. Round dark spots with diffuse edges are observed on a bright background, as a result of the electron-microscopic absorption contrast from clusters enriched by iron. The sizes of the dark spots are unaffected but the density of darkening decreases after quenching from $1000^{\circ} \mathrm{C}$ (Figure 22(a)).

At lowering the heat treatment temperature to $450^{\circ} \mathrm{C}$, i.e. to a temperature below the line of the phase transition ordering-phase separation, a system of additional reflections appears in the electron diffraction patterns (Figure 22(b)), evidencing the nucleation of highly-dispersed particles of a new L $1_{2}$ phase (usually called the $\gamma^{\prime}$-phase) on the $\{110\}$ planes of the disordered matrix. The reflections are rather weak.

The formation of reflections from particles of the $\mathrm{L} 1_{2}$ phase alongside with almost complete absence of contrast from these particles made authors [59] assume that this occurs due to the fact that the crystal lattice of the particles of this phase is fully coherent with the lattice of the surrounding fcc solid solution. So, in alloys of the permalloy class, aged in the temperature range of $450^{\circ} \mathrm{C}-500^{\circ} \mathrm{C}$, highly-dispersed particles of the L12 $\left(\gamma^{\prime}\right)$ phase precipitate from the solid solution as a consequence of the tendency of these alloys to ordering at such temperatures.

\subsection{Consequences Following from the Obtained Results}

According to existing ideas, at high temperatures, the microstructure of ordering alloys is a homogeneous solid solution, in which component atoms are randomly distributed over lattice sites (for substitution alloys) and in- 


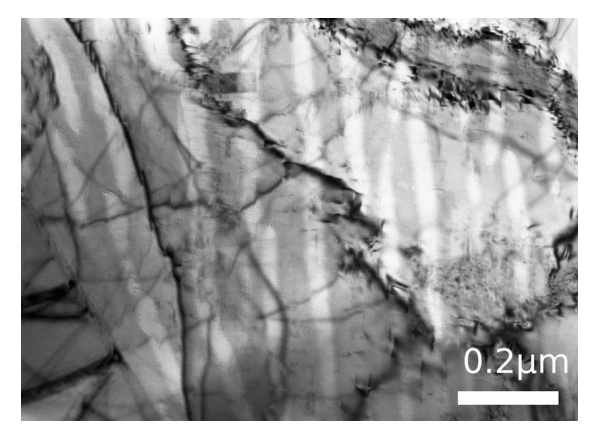

Figure 20. $\mathrm{Fe}_{68} \mathrm{Ni}_{32}$ alloy aged at $740^{\circ} \mathrm{C}$. Bright-field images of a microstructure.

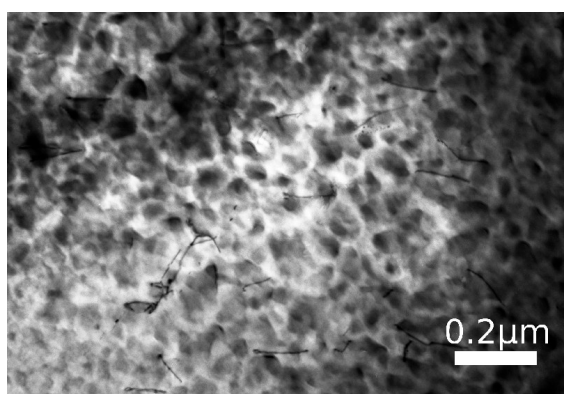

Figure 21. $\mathrm{Fe}_{23} \mathrm{Ni}_{77}$ alloy. Water-quenching from $1300^{\circ} \mathrm{C}$. Bright-field images of a microstructure obtained from the majority of microscopic portions of the foil.
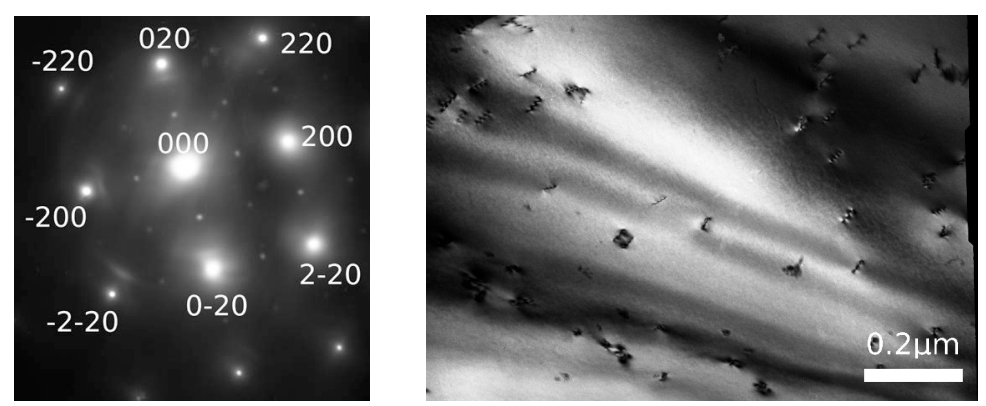

Figure 22. $\mathrm{Fe}_{23} \mathrm{Ni}_{77}$ alloy. Water-quenching from $1000^{\circ} \mathrm{C}$. Bright-field image of a microstructure (a); electron diffraction pattern; zone axis is near $[001]_{\mathrm{A} 1} ;(100)_{\mathrm{A} 1} / /(100)_{\mathrm{L} 12} ;[010]_{\mathrm{A} 1} / /[110]_{\mathrm{L} 12}$ (b).

terstices (for interstitial alloys). At a temperature decrease, when the alloy becomes supersaturated with the alloying component, an order-disorder phase transition begins in it. It is considered that the physical reason of ordering is the elastic interaction between atoms of the components constituting the solid solution [1]. At low temperatures, when the atomic interaction potential becomes significantly higher than heat energy, the mutual arrangement of component atoms in the solid solution will be determined from the minimum free energy condition [1] and a new phase will form.

However, the type and dispersity of the microstructure do not directly depend on heat treatment temperature as it was previously supposed on the basis of the fact that, for example, in aqueous solutions, the degree of their supersaturation gradually decreases with a progressive increase in the temperature. In metal alloys, a more complicated dependence of the forming microstructure on the temperature of heating takes place, which appears as a consequence of the existence of the phase transition ordering-phase separation in alloys. This is indicated by, at least, the facts that after quenching from high temperatures, a two-phase microstructure instead of the microstructure of the solid solution has been found in many alloys, and, at a decrease of the temperature, one could, on the contrary, observe the solid solution structure in a number of alloys (if the phase transition ordering-phase separation took place at low temperatures). Experimental discovery of the phase transition ordering-phase separation in alloys has shown that the type of the alloy microstructure is directly dependent on the sign of the ener- 
gy of the chemical interaction, and the possibility of formation of the solid solution structure depends on the absolute magnitude of the energy of the chemical interaction at the test temperature. At the same time, the last two parameters (the sign and the absolute magnitude of the energy of chemical interaction) are directly dependent on the temperature.

The scheme presented in Figure 23, shows how the sign and the absolute magnitude of the energy of the chemical interaction $\mathrm{E}$ change at temperature changes, in the presence of two phase transitions ordering-phase separation in the $\mathrm{Fe}_{50} \mathrm{Cr}_{50}$ alloy (at $560^{\circ} \mathrm{C}$ and $1000^{\circ} \mathrm{C}$ ). Dashed lines 3, 4, 5 correspond to the level of the chemical interaction energy (in absolute value), above which a new phase precipitates in the alloy (chromium rich clusters or the $\sigma$-phase). The points of intersection of these lines $(3,4,5)$ with curve E correspond to the points in the Fe-Cr phase diagram (Figure 4) that separate single-phase and two-phase regions.

The sizes of dissimilar atoms constituting the alloy do not play that determining role in the processes of formation of new phases or formation of the solid solution that is usually attributed to them, referring to the $15 \%$ rule. Evidence of that can be found by examining the obtained experimental results in sections 3.1 - 3.7. Some of the diffusion couples of alloy components presented in these sections have a difference in the sizes of atoms which is significantly higher than $15 \%$, in others the difference is quite small, but in all of them (except the Ni-V system), a phase transition "ordering-phase separation" with corresponding changes in microstructure occurs.

Using this scheme, and based on the results presented above (3.1 - 3.7), we can make the following conclusions:

1) Chemical interaction between dissimilar atoms exists always, in all alloys and at any temperature of heating.

2) The sign of the energy of the chemical interaction between dissimilar atoms is not a constant for the majority of metallic systems but varies with the change of the temperature of the alloy (sometimes more than once).

3) Precipitation of this or that phase and formation of a solid solution depends not on the degree of solubility of atoms of one component in the lattice of the other, but on the sign and the absolute magnitude of the energy of the chemical interaction between dissimilar atoms.

4) The exposure of the alloy at each heating temperature brings to formation of quite definite microstructure unique to this temperature, during which the previous microstructure is not inherited and disappears. This means that quenching of alloys from the so-called region of the solid solution, which is usually performed before tempering (aging) is a totally unnecessary and useless operation that does not in any way affect the final structure of the alloy forming later at the temperature of tempering (aging).

5) The microstructure of a disordered solid solution is formed over all the bulk of an alloy only in the temperature region adjacent to the temperature of the phase transition "ordering-phase separation", because it is in this region that the chemical interaction energy between dissimilar atoms is close to zero.

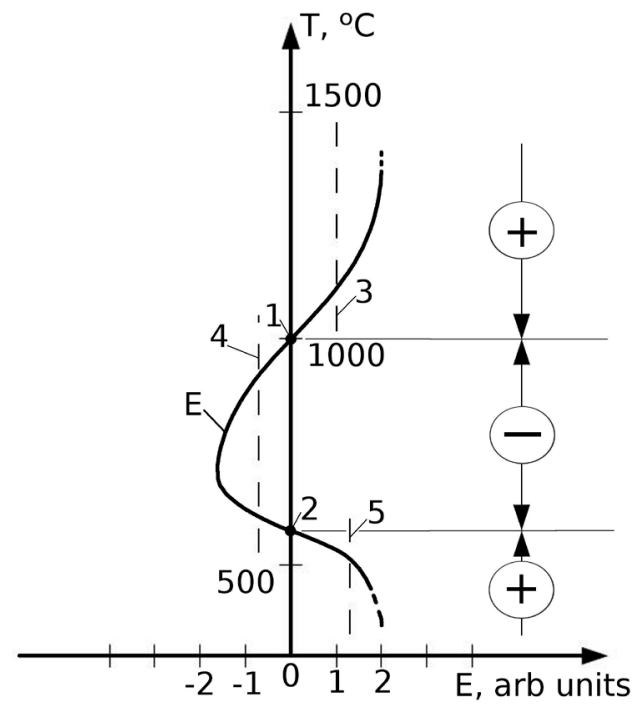

Figure 23. The energy of the chemical interaction vs. temperature for $\mathrm{Fe}_{50} \mathrm{Cr}_{50}$ alloy. 1, 2 -points of high-temperature (1) and low-temperature (2) phase transitions ordering-phase separation. 


\section{Conclusions}

The discovery of the phase transition "ordering-phase separation" opens new perspectives for Materials Science in the study of alloys and sets new problems.

1) Our understanding of this or that physical phenomenon always changes with time and usually corresponds to the level of experimental technique at the given period. However, some theories and views which formed many years ago (when the modern research methods did not yet exist) persisted to the present. They have so deeply rooted into our minds, that even now, when the experiment does not verify them, we believe that they are the unquestionable truth. For example, we cannot imagine equilibrium phase diagrams without regions of solid solutions at high temperatures, although the latter, from the point of view of thermodynamics, is not an equilibrium phase at any temperature. We cannot imagine the probability of decomposition of a quenched solid solution without its "supersaturation" in the alloying component, which occurs at a decrease of the solution temperature. We cannot imagine a heat treatment carried out to obtain a highly dispersed two-phase structure, which will not include a preliminary high-temperature quenching from the solid solution region. The discovery of the phase transition "ordering-phase separation" in alloys makes us look more critically at some ideas existing in Materials Science, and to understand that it is precisely the chemical interactions between dissimilar atoms and their dependence on the transition temperature that are the source of all structural changes in alloys.

2) As known, any solutions A(B) are not ideal, and therefore, in certain conditions, they are bound to decompose indiscriminately. This axiom of thermodynamics has long been known, and it applies to all solid solutions in metallic alloys. At the same time, the majority of equilibrium phase diagrams constructed to date for A-B metallic systems, contain solid solution regions, especially at high temperatures, when the diffusion mobility of A and B atoms and their energy of the chemical interaction are sufficient for their decomposition. Thus, in the existing equilibrium phase diagrams, regions are presented, in which the phase (solid solution) is not an equilibrium one.

3) The phase transition "ordering-phase separation" takes place in vast majority of alloys and consists in the fact that at a heat treatment temperature, which is definite for each system, the sign of the energy of the chemical interaction between dissimilar atoms constituting the alloy changes. The change of the sign of the chemical interaction that occurs at the level of changes in the electronic structure, determines a change in the type of microstructures: if a tendency to ordering is displayed in the alloy, then chemical compounds are formed in the microstructure. If a tendency to phase separation is displayed in the alloy, then clusters (or grains) appear, consisting mainly of atoms of one kind. In the phase transition point, the energy of the chemical interaction of the alloy is equal to zero and, therefore, at temperatures close to this point, a structural state, close to the disordered solid solution, is formed in all the bulk of an alloy. The temperature of the phase transition "ordering-phase separation" is different for different systems.

4) In this paper, we present numerous examples showing, that the actual microstructure of alloys after high temperature quenching from the so-called solid solution region does not correspond to their phase diagrams. Existence of the phase transition indicates that old ideas about the decomposition of alloys occurring due to a decrease in the solubility along with a temperature decrease do not correspond to reality, and hence, phase diagrams constructed on the basis of such principles do not reflect the real picture of decomposition processes taking place in alloys. A correction of phase diagrams should start with experimental detection of the temperature of the phase transition "ordering-phase separation". In most systems, this temperature is the same for all compositions, but in some systems, it may vary with a change in the concentration.

5) Some different approach to the heat treatment of alloys is proposed, which become possible after the experimental discovery of the phase transition "ordering-phase separation" in alloys. Quenching of alloys from the so-called region of the solid solution, which is usually performed before tempering (aging) is a totally unnecessary and useless operation that does not in any way affect the final structure of the alloy forming later at the temperature of tempering (aging).

\section{Acknowledgments}

The work was supported by the Ural Branch of Russian Academy of Sciences (Grant No 12-Y-2-1009).

\section{References}

[1] Khachaturyan, A.G. (1983) Theory of Structural Transformation in Solids. John Wiley \& Sons Inc., Hoboken. 
[2] Chevalier, J.P. and Stobbs, W.M. (1976) An Electron Diffraction Study of Short-Range Order in Quenched Ni $\mathrm{Mo} \mathrm{Al-}_{4}$ loys. Acta Metallurgica, 24, 535-542. http://dx.doi.org/10.1016/0001-6160(76)90098-5

[3] Higgins, J., Nicholson, R.B. and Wilkes P. (1974) Precipitation in Iron-Beryllium System. Acta Materialia, 22, 201217.

[4] Laughlin, D.E. and Cahn, J.W. (1975) Spinodal Decomposition in Age-Hardening Cu-Ti Alloys. Acta Materialia, 23, 329-339.

[5] Phillips, L.A. and Tanner, L.E. (1973) High-Resolution Electron Microscopy Observations on GP Zones in an Aged Cu-2 wt\% Be Crystal. Acta Materialia, 21, 441-448.

[6] Flewitt, P.E. (1974) Phase Transformations in Nb 16 to 40\% Zr Alloys above the Monotectoid Temperature. Acta Materialia, 22, 47-63.

[7] Guinier, A. (1963) X-Ray Diffraction in Crystals, Imperfect Crystals, and Amorphous Bodies. W. H. Freeman, SanFrancisco.

[8] Ustinovshikov, Y., Shirobokova, M. and Pushkarev, B. (1996) A Structural Study of the Fe-Cr System Alloys. Acta Metallurgica, 44, 5021-5032. http://dx.doi.org/10.1016/S1359-6454(96)00088-2

[9] Ustinovshikov, Y., Lomova, N. and Shabanova, I. (2008) High-Temperature B2 Ordering in $\mathrm{Fe}_{50} \mathrm{Co}_{50}$ Alloy. Journal of Physics and Chemistry of Solids, 69, 1753-1757. http://dx.doi.org/10.1016/j.jpcs.2007.12.010

[10] Ustinovshikov, Y., Shabanova, I. and Lomova, N. (2013) TEM Study of the “Ordering-Phase Separation” Transition in Ni-Co Alloys. Journal of Advanced Microscopy Research, 8, 27-32. http://dx.doi.org/10.1166/jamr.2013.1132

[11] Ustinovshikov, Y. (2014) Diffusion Phase Transitions in Alloys. Physics-Uspekhi, 184, 723-737.

[12] Ustinovshikov, Y. (2010) “Chemical” Phase Transition in Alloys: Ordering-Phase Separation. Current Opinion in Solid State and Materials Science, 14, 7-20. http://dx.doi.org/10.1016/j.cossms.2009.08.002

[13] Ustinovshikov, Y., Pushkarev, B. and Sapegina, I. (2005) Condition of Existence of a Disordered Solid Solution Having Chemical Interactions between Atomic Species. Journal of Alloys and Compounds, 394, 200-206. http://dx.doi.org/10.1016/j.jallcom.2004.10.033

[14] Jeannin, Y., Mannerskantz, C. and Richardson, F.D. (1963) Activities in Iron-Chromium Alloys. Transactions Met. Soc. AIME, 227, 300-305.

[15] Massalski, T.B. (1990) Binary Alloy Phase Diagrams. ASM International, Metals Park.

[16] Ustinovshikov, Y. and Pushkarev, B. (1998) Morphology of Fe-Cr Alloys. Materials Science and Engineering: A, 241, 159-168. http://dx.doi.org/10.1016/S0921-5093(97)00484-X

[17] Ustinovshikov, Y., Pushkarev, B. and Igumnov, I. (2002) Fe-Rich Portion of the Fe-Cr Phase Diagram: Electron Microscopy Study. Journal of Materials Science, 37, 2031-2042. http://dx.doi.org/10.1023/A:1015259517812

[18] Kosythyna, I.I., Sagaradze, V.V., Raspopova, G.A. and Kabanova, I.G. (2001) Formation of Own and Foreign Phases at Heat Treatment of Fe-Cr alloys. Russian Metallurgy (Metally), 1, 49-56.

[19] Le Caer, G., Delcroix, P. and Costa, B.F.O. (2007) Mossbauer Spectrometry of Near Equiatomic Fe-Cr Alloys: Phase Separation at High Temperature? Journal of Alloys and Compounds, 434, 587-589. http://dx.doi.org/10.1016/j.jallcom.2006.08.086

[20] Frattini, F., Longworth, G., Matteazzi, P., Principi, G. and Tiziani, A. (1981) Mossbauer Studies of Surface Sigma Phase Formation in an Fe-45Cr Alloy Heated in Low Partial Oxigen Pressure. Scripta Materialia, 15, 873-877. http://dx.doi.org/10.1016/0036-9748(81)90269-6

[21] Ishimasa, T., Kitano, Y. and Komura, Y. (1981) Electron Microscope Observation of Lattice Defects in the Fe-Cr $\sigma$-Phase. Journal of Solid State Chemistry, 36, 74-80. http://dx.doi.org/10.1016/0022-4596(81)90193-6

[22] Turchi, P.E.A., Reinhard, L. and Stocks, G.M. (1994) First-Principles Study of Stability and Local Order in Bcc-Based Fe-Cr and Fe-V Alloys. Physical Review B, 50, 15542-15558. http://dx.doi.org/10.1103/PhysRevB.50.15542

[23] DeNys, T. and Gielen, P.M. (1971) Spinodal Decomposition in the Fe-Cr System. Metallurgical Transactions, 2, 14231428.

[24] Ohnuma, I., Enoki, H., Kainuma, R., Ohtani, H. and Ishida, K. (2002) Phase Equilibria in the Fe-Co Binary System. Acta Materialia, 50, 379-388. http://dx.doi.org/10.1016/S1359-6454(01)00337-8

[25] Ustinovshikov, Y. and Pushkarev, B. (2005) Alloys of the Fe-Cr System: The Relation between Phase Transitions “Order-Disorder” and “Ordering-Separation”. Journal of Alloys and Compounds, 389, 95-101. http://dx.doi.org/10.1016/j.jallcom.2004.07.050

[26] Ustinovshikov, Y., Pushkarev, B. and Sapegina, I. (2005) Phase Separation in the Fe-Mn System. Journal of Alloys and Compounds, 399, 160-165. http://dx.doi.org/10.1016/j.jallcom.2005.03.024

[27] Ustinovshikov, Y., Igumnov, I. and Pushkarev, B. (1999) The Nature of the Periodic Microstructure in Fe-Ti Alloys. 
Materials Science and Engineering: A, 259, 105-109. http://dx.doi.org/10.1016/S0921-5093(98)00866-1

[28] Ustinovshikov, Y., Pushkarev, B. and Sapegina, I. (2005) Phase Transformation in Alloys of the Fe-V System. Journal of Alloys and Compounds, 398, 133-138. http://dx.doi.org/10.1016/j.jallcom.2005.02.030

[29] Ustinovshikov, Y. (2011) Decomposition of the Fe-(6-20) at\% Mo Alloys. Materials Chemistry and Physics, 125, 908-911. http://dx.doi.org/10.1016/j.matchemphys.2010.07.054

[30] Ustinovshikov, Y. and Sapegina, I. (2004) Separation in Solid Solutions of Fe-W System. Journal of Materials Science, 39, 6233-6242. http://dx.doi.org/10.1023/B:JMSC.0000043592.95047.b8

[31] Ustinovshikov, Y. (2009) About Fe-C Diagram. Russian Metallurgy (Metally), 5, 81-85.

[32] Houdremont, E. (1956) Handbuch der Sonderstahlkunde. Springer Verlag, Berlin.

[33] Izotov, V.I. and Utevsky, L.M. (1968) Structure of Martensite Crystals of High-Carbon Steel. Physics of Metals and Metallography, 25, 98-110.

[34] Nagakura, S., Shiraishi, K. and Toyoshima, M. (1979) Crystal Structure and Morphology of the Ordered Phase in Iron-Carbon Martensite. Transactions Japan Institute of Metals, 20, 100-110.

[35] Kusunoki, M. and Nagakura, S. (1981) Modulated Structure of Iron-Carbon Martensite Studied by Electron Microscopy and Diffraction. Journal of Applied Crystallography, 14, 329-336. http://dx.doi.org/10.1107/S0021889881009485

[36] Tyapkin, Y.D., Georgieva, I.Y., Golikov, V.A. and Gulyaev, A.A. (1975) Modulated Structure of High-Carbon Martensite. Physics-Doklady, 221, 335-338.

[37] Sandvik, B.P.J. and Wayman, C.M. (1983) Direct Observation of Carbon Clusters in a High-Carbon Martensitic Steel. Metallography, 16, 429-447. http://dx.doi.org/10.1016/0026-0800(83)90031-9

[38] Ustinovshikov, Y. and Pushkarev, B. (2006) Diffusive Phase Transformations: Example of Fe-M Alloys. Journal of Alloys and Compounds, 422, 116-127.

[39] Fang, L., Xiao, F., Wang, Y.F., Tao, Z.N. and MuKai, K. (2006) Density and Molar Volume of Liquid Ni-Co Binary Alloys. Materials Science and Engineering: B, 132, 174-178. http://dx.doi.org/10.1016/j.mseb.2006.02.015

[40] Ichise, E., Shaw, K. and Taniguchi, S. (1993) Thermodynamic Study on Liquid Binary Alloys of Co, Cr and Ni. The Mass Spectrometry Society of Japan, 41, 343-350.

[41] Ustinovshikov, Y. (2014) A New Paradigm for Heat Treatment of Alloys. Journal of Alloys and Compounds, 614, 258-263.

[42] Ustinovshikov, Y. and Shabanova, I. (2011) Phase Transitions in Alloys of the Ni-Mo System. Materials Chemistry and Physics, 129, 975-980.

[43] Ustinovshikov, Y. and Shabanova, I. (2012) Nature of High Hardness in the $\mathrm{Co}_{70} \mathrm{Mo}_{30}$ Alloy. Materials Chemistry and Physics, 135, 254-258.

[44] Das, S.K., Okamoto, P.R., Fisher, P.M. and Thomas, J. (1973) Short Range Order in Ni-Mo, Au-V and Au-Mn Alloys. Acta Metallurgica, 21, 913-928. http://dx.doi.org/10.1016/0001-6160(73)90149-1

[45] Van Tendeloo, G., Amelinkx, S. and De Fontaine, D. (1985) On the Nature of the "Short-Range Order" in 1 1/2 0 Alloys. Acta Crystallographica, 41, 281-292. http://dx.doi.org/10.1107/S0108768185002166

[46] Banergee, S. (2003) In-situ Studies on Phase Transformation under Electron Irradiation in a High Voltage Electron Microscope. Sadhana, 28, 799-814. http://dx.doi.org/10.1007/BF02706460

[47] Nesbit, L.A. and Laughlin, D.E. (1981) Solid State Morphological Instability of $\mathrm{Ni}_{4}$ Mo Precipitates. Journal of Crystal Growth, 51, 273-278. http://dx.doi.org/10.1016/0022-0248(81)90310-9

[48] Ustinovshikov, Y. (2012) Phase Transition “Ordering-Phase Separation” in the Ni-12 at\% Al Alloy. Journal of Alloys and Compounds, 528, 141-145.

[49] Ustinovshikov, Y. and Shabanova, I. (2013) A Study of Microstructures Responsible for the Emergence of the Invar and Permalloy Effects in Fe-Ni Alloys. Journal of Alloys and Compounds, 578, 292-296.

[50] Ustinovshikov, Y. (2012) Phase Transformations in Alloys of the Ni-Cr system. Journal of Alloys and Compounds, 543, 227-232.

[51] Ustinovshikov, Y. (2015) Phase Transition “Ordering-Phase Separation” in Alloys of Ni-Cr system. Materials Chemistry and Physics, in press.

[52] Singh, J.B., Sundararaman, M., Mukhopadhyay, P. and Prabhu, N. (2003) Evolution of Microstructure in the Stoichiometric Ni-25 at\% V Alloy. Intermetallics, 11, 83-92. http://dx.doi.org/10.1016/S0966-9795(02)00186-3

[53] Kaneno, Y., Soga, W., Tsuda, H. and Takasugi, T. (2008) Microstructural Evolution and Mechanical Property in Dual Two-Phase Intermetallic Alloys Composed Geometrically Close-Packed $\mathrm{Ni}_{3} \mathrm{X}(\mathrm{X}=\mathrm{Al}$ and $\mathrm{V}$ ) Containing Nb. Journal of Materials Science, 43, 748-758. 
[54] Suzuki, A., Kojima, H., Matsuo, T. and Takeyama, M. (2004) Alloying Effect on Stability of Multi-Variant Structure of $\mathrm{Ni}_{3} \mathrm{~V}$ at Elevated Temperatures. Intermetallics, 12, 969-975. http://dx.doi.org/10.1016/j.intermet.2004.02.028

[55] Ustinovshikov, Y. (2013) Evolution of the Microstructure of $\mathrm{Ni}_{75} \mathrm{~V}_{25}$ and $\mathrm{Ni}_{75} \mathrm{~V}_{20} \mathrm{Al}_{5}$ Alloys at Changing the Temperature of Their Heat Treatment. Journal of Alloys and Compounds, 575, 10-16.

[56] Wohlfarth, E.P. (1979) Invar Behavior in Crystalline and Amorphous Alloys. Journal of Magnetism and Magnetic Materials, 10, 120-125. http://dx.doi.org/10.1016/0304-8853(79)90162-8

[57] Wasserman, E.F. (1991) Invar Moment-Volume Instabilities in Transition Metals and Alloys. Journal of Magnetism and Magnetic Materials, 100, 346-362.

[58] Ducki, K.J. (2007) Structure and Precipitation Strengthening in a High Tempering Fe-Ni Alloy. J. Mater. Manuf. Eng., 21, 25-28.

[59] Ustinovshikov, Y.and Shabanova, I. (2013) A Study of Microstructures Responsible for the Emergence of the Invar and Permalloy Effects in Fe-Ni Alloys. Journal of Alloys and Compounds, 578, 292-296. 